\title{
Stratospheric sudden warming effects on winds and temperature in the middle atmosphere at middle and low latitudes: a study using WACCM
}

\author{
A. Chandran ${ }^{1}$ and R. L. Collins ${ }^{1,2}$ \\ ${ }^{1}$ Geophysical Institute, University of Alaska Fairbanks, Fairbanks, Alaska, USA \\ ${ }^{2}$ Department of Atmospheric Sciences, University of Alaska Fairbanks, Fairbanks, Alaska, USA
}

Correspondence to: A. Chandran (achandran@alaska.edu)

Received: 21 December 2013 - Revised: 13 May 2014 - Accepted: 19 June 2014 - Published: 28 July 2014

\begin{abstract}
A stratospheric sudden warming (SSW) is a dynamical phenomenon of the wintertime stratosphere caused by the interaction between planetary Rossby waves propagating from the troposphere and the stratospheric zonal-mean flow. While the effects of SSW events are seen predominantly in high latitudes, they can also produce significant changes in middle and low latitude temperature and winds. In this study we quantify the middle and low latitude effects of SSW events on temperature and zonal-mean winds using a composite of SSW events between 1988 and 2010 simulated with the specified dynamics version of the Whole Atmosphere Community Climate Model (WACCM). The temperature and wind responses seen in the tropics also extend into the low latitudes in the other hemisphere. There is variability in observed zonal-mean winds and temperature depending on the observing location within the displaced or split polar vortex and propagation direction of the planetary waves. The propagation of planetary waves show that they originate in mid-high latitudes and propagate upward and equatorward into the mid-latitude middle atmosphere where they produce westward forcing reaching peak values of $\sim 60$ $70 \mathrm{~m} \mathrm{~s}^{-1}$ day $^{-1}$. These propagation paths in the lower latitude stratosphere appear to depend on the phase of the quasibiennial oscillation (QBO). During the easterly phase of the QBO, waves originating at high latitudes propagate across the equator, while in the westerly phase of the QBO, the planetary waves break at $\sim 20-25^{\circ} \mathrm{N}$ and there is no propagation across the equator. The propagation of planetary waves across the equator during the easterly phase of the QBO reduces the tropical upwelling and poleward flow in the upper stratosphere.
\end{abstract}

Keywords. Meteorology and atmospheric dynamics (general circulation, middle atmosphere dynamics)

\section{Introduction}

A stratospheric sudden warming (SSW) is a dynamical phenomenon of the wintertime middle atmosphere that involves dramatic reversals of the temperature gradient, zonal-mean winds and meridional circulation in the stratosphere and mesosphere. The mechanism for SSW events, first proposed by Matsuno (1970), involves the upward propagation of planetary waves from the troposphere, which decelerate or reverse the eastward zonal-mean flow in the stratosphere. The planetary waves thus drive the meridional circulation, inducing upwelling (and adiabatic cooling) over the equator and downwelling (warming) over the poles in the stratosphere (Garcia, 1987). The breaking wintertime planetary waves thus act to enhance the Brewer-Dobson circulation. Because of the reversal of the stratospheric jet in mid-high latitudes from eastward to westward, the gravity wave forcing in the polar mesosphere and lower thermosphere (MLT) also reverses during this period due to filtering of westward-propagating gravity waves and penetration of eastward-propagating gravity waves into the mesosphere (Siskind et al., 2007, 2010; Chandran et al., 2011). In the mesosphere the eastward gravity waves drive upwelling and adiabatic cooling at high latitudes and downwelling and adiabatic warming over the equator. The changes in residual circulation in the stratosphere and mesosphere also affect the concentration of atmospheric constituents in the stratosphere and MLT region (Siskind et al., 2007; Manney et al., 
2009, 2011; Marsh, 2011, and references therein). Extensive observational and theoretical studies have shown changes in the troposphere-stratosphere-mesosphere-thermosphere and ionosphere during SSW events (Baldwin and Dunkerton, 2001; Chandran et al., 2011; Goncharenko et al., 2010).

An SSW is defined by the World Meteorological Organization (WMO) as a reversal of the poleward temperature gradient from $60^{\circ}$ latitude to the pole accompanied by a reversal of the zonal-mean zonal wind at $60^{\circ}$ latitude at or below $10 \mathrm{hPa}$. While the effects of SSW are predominantly seen at high latitudes, where the changes in residual circulation are magnified due to the smaller area compared to middle and low latitudes, SSW effects can also be seen in middle and low latitudes as well as in the other hemisphere through inter-hemispheric coupling mechanisms (Karlsson et al., 2009; Kornich and Becker, 2010). Fritz and Soules (1970) showed equatorial cooling in the stratosphere associated with a stratospheric warming using satellite data. Pawson et al. (1995) used a general circulation model under perpetual January conditions to show that SSW events have an impact on the equatorial middle atmosphere. Kodera (2006) showed that a warming of the equatorial stratosphere and upper troposphere during an SSW can lead to a suppression of convective activity in the tropical Northern Hemisphere $\left(5-15^{\circ} \mathrm{N}\right)$ and enhancement in the tropical equatorial Southern Hemisphere (equator- $10^{\circ} \mathrm{S}$ ).

Recently there have been a number of observational studies describing the wind and temperature changes in the middle atmosphere from mid- and low latitude sites. Hoffman et al. (2007) used multiple wind measurements at mid-high latitude sites $\left(75\right.$ to $\left.54^{\circ} \mathrm{N}\right)$ and characterized latitudinal and longitudinal variability during the SSW events of 20052006 and 1998-1999. Hoffman et al. (2007) concluded that the strength of wind reversal decreases with latitude, and they found only weak longitudinal variations in zonal-mean wind and temperature at mesopause heights. However, they found strong longitudinal variations in meridional winds. Yuan et al. (2012) reported changes in mesospheric zonalmean winds and temperature from lidar observations from a mid-latitude location (Fort Collins, $41^{\circ} \mathrm{N}$ and $105^{\circ} \mathrm{W}$ ) during the 2009 major SSW event in January. Yuan et al. (2012) found significant anomalies from climatological means with temperature anomalies as low as $30 \mathrm{~K}$ from climatological mean and zonal-mean wind turning eastward in the lower thermosphere in a reversal of climatological mean wind profile, which were directly attributed to the SSW. Chen et al. (2012) reported changes in the wind structure during the SSW events of 2000-2001 over Wuhan $\left(30^{\circ} \mathrm{N}\right)$ and 2009 2010 over Langfang $\left(39^{\circ} \mathrm{N}\right)$ and found variability in wind responses at the two sites. Sathishkumar et al. (2009) also reported low and mid-latitude winds during the SSW events of 1998-1999, 2003-2004, and 2005-2006. Sathishkumar et al. (2009) found differences in the behavior of MLT winds at Tirunelveli $\left(8.7^{\circ} \mathrm{N}, 77.8^{\circ} \mathrm{E}\right)$ and Collm $\left(52^{\circ} \mathrm{N}\right.$, $\left.15^{\circ} \mathrm{E}\right)$ and attributed the differences to variability in local gravity wave activity during the SSW events. Sathishkumar and Sridharan (2009) also found that the mean meridional wind observed at Tirunelveli $\left(8.7^{\circ} \mathrm{N}\right)$ became more equatorward during the 2005-2006 event as compared to the 19981999 event. Observations at Gadanki $\left(13.5^{\circ} \mathrm{N}, 79.2^{\circ} \mathrm{E}\right)$ have shown increases in the mesospheric temperature and gravity wave activity (Sridharan et al., 2010) and a change in the direction of mesospheric gravity wave propagation from westward to eastward (Nath et al., 2013) during the 2009 SSW. Butler and Polvani (2011) found that SSW events are nearly twice as frequent during El Niño-Southern Oscillation (ENSO) winters than during non-ENSO winters, while SSWs occur with equal probability during El Niño and La Niña winters.

The propagation of planetary waves into the lower latitude stratosphere and mesosphere and their effect on midand low latitude winds have also been a topic of recent interest. Matthias et al. (2013) find a continuous band of westward wind extending from the pole to the tropics in the stratosphere during the SSW events of 2009, 2010 and 2012, while no such band exists in 2006. Matthias et al. (2013) attribute the differences between SSW events to increased planetary wave activity between 30 and $50^{\circ} \mathrm{N}$. Vineeth et al. (2010) showed a latitudinal connection between low and high latitudes through the presence of a quasi-16-day wave during the 2003-2004 and 2005-2006 SSW and speculated that this might be due to the phase of the quasi-biennial oscillation (QBO). They however concluded that there was wave propagation from the equator to the pole during SSW, which modulates the zero wind line at $10 \mathrm{hPa}$. Recently Gómez-Escolar et al. (2014), in their study of the response of the tropical stratosphere to SSW, found that tropical cooling during the westerly phase of the QBO persists longer in the upper stratosphere (above $40 \mathrm{hPa}$ ), while, during the easterly phase of the QBO, enhanced cooling occurs in the lower stratosphere (below $50 \mathrm{hPa}$ ).

In this study, we simulate SSW events between 1988 and 2010 using the specified dynamics version of the Whole Atmosphere Community Climate Model (SD-WACCM) and build a composite of the zonal-mean temperature and winds from all major SSW events during the period of simulation to quantify the temperature and zonal-mean wind anomalies from their climatological means at high $\left(60-90^{\circ} \mathrm{N}\right)$, middle $\left(30-60^{\circ} \mathrm{N}\right)$ and low latitudes $\left(0-30^{\circ} \mathrm{N}\right)$. Using a fully coupled chemistry-climate global circulation model such as WACCM offers a global perspective which can be used to explain the response to SSW events that have been reported from sites at different latitudes (e.g., Hoffman et al., 2007; Sathishkumar and Sridharan, 2009; Yuan et al., 2012). We show the latitudinal response in zonal-mean temperatures and winds during two case studies of the 2006 and 2009 SSW events to compare with the composite from multiple events. Since the QBO is a major source of stratospheric variability in the tropics (e.g., Baldwin et al., 2011) and can modulate the propagation of planetary waves across the tropics 
(Ortland, 1997; O’Sullivan, 1997), we investigate differences in planetary wave propagation in the low latitude stratosphere in two winters that are in different phases of the QBO during SSW events. We also investigate the effect of variation in planetary wave propagation in the tropics on the residual circulation and its effect on the tropical stratospheric cooling observed during SSW events. Finally, we show the modelsimulated variability in temperature and winds at three locations covering high, middle and low latitudes during the 2006 and 2009 SSW events. We discuss the differences in evolution of the middle atmosphere temperature and wind structure at these sites with respect to their location within the disturbed polar vortex.

\section{The Whole Atmosphere Community Climate Model (SD-WACCM)}

The version of SD-WACCM (WACCM v3.48) used in this study is a fully coupled chemistry-climate general circulation model, derived from the Community Atmosphere Model (CAM3) developed at the National Center for Atmospheric Research (NCAR). The model domain extends from the Earth's surface to $\sim 145 \mathrm{~km}\left(4.5 \times 10^{-6} \mathrm{hPa}\right)$ and has a horizontal resolution of $1.9^{\circ} \times 2.5^{\circ}$ (latitude $\times$ longitude). To reproduce observed meteorological phenomena like SSW events, WACCM can be run with the model dynamical and temperature fields in the troposphere and stratosphere constrained by relaxing the horizontal winds and the temperature to GEOS-5.2 reanalysis data from the surface to $40 \mathrm{~km}$. The strength of the relaxation is linearly reduced between 40 and $50 \mathrm{~km}$, such that the model becomes free running above $50 \mathrm{~km}$. This version of WACCM is referred to as specified dynamics WACCM, or SD-WACCM and has been previously used by Marsh (2011) and Chandran et al. (2013b) to study the major SSW of 2006 and the minor SSW of 2012, respectively. SD-WACCM has 88 vertical levels, with a resolution of approximately two grid-points per scale height in the MLT. In this study, we have used SD-WACCM simulations between January 1988 and May 2011 to identify multiple major SSW events. These major SSW events include both vortex displacement and vortex splitting events as well as major SSW events during the west and east phases of the QBO.

Planetary waves and other large-scale waves are resolved in WACCM, while the effect of mesoscale orographic and non-orographic small-scale gravity waves is parameterized (Garcia et al., 2007; Richter et al., 2008, 2010). The Eliassen-Palm (EP) flux divergence due to planetary-scale Rossby waves is determined from the daily output of the model using established definitions (Andrews et al., 1987). The daily output does not include daily values of gravity wave forcing, which are instead inferred as a residual in the transformed Eulerian mean (TEM) zonal momentum budget (Andrews et al., 1987). This approach to determining gravity wave forcing has been used in analysis of both observations and models (Liu et al., 2009; Chandran et al., 2011). WACCM has been previously shown to reproduce both SSW and elevated stratopause events in long-term climatological simulations with occurrence frequencies close to observations (de la Torre et al., 2012; Chandran et al., 2013a) and hence provides a comprehensive tool for studying the latitudinal response in the mid-atmosphere winds and temperatures.

\section{Results}

\subsection{A composite view of SSW effects on mid- and low latitude temperature and winds}

To investigate the effects of SSWs on mid- and low latitude temperature and winds, we make a composite of all major SSWs between 1988 and 2010 from SD-WACCM and compare the differences in the mid- and low latitude temperature and winds with respect to climatological values. The climatological values of zonal-mean temperature and winds are calculated as the 22-year (1988-2010) seasonal average over the winter months of December, January and February. The climatological zonal-mean temperature $(T)$, zonal wind $(U)$ and meridional wind $(V)$ are shown in Fig. 1a, b and $\mathrm{c}$ respectively. The normal wintertime separated polar stratopause (Fig. 1a), the eastward zonal-mean stratospheric winds and westward upper MLT zonal winds (Fig. 1b) and the poleward meridional wind in the mesosphere in the Northern Hemisphere can be clearly seen. It should be noted that observations at single site locations during specific winters do not always show the MLT westward wind (e.g., Hoffman et al., 2007; Matthias et al., 2013). The westward MLT wind reversal shown in WACCM climatology, however, agrees with climatological observations at $40^{\circ} \mathrm{N}$ shown in Yuan et al. (2008) and with zonal-mean winds shown in SSW studies using reanalysis data from MERRA (Chandran et al., 2013a) and ECMWF (Salmi et al., 2011). The radar do not usually report winds above $90 \mathrm{~km}$ and hence might not detect the westward MLT wind reversal. Alternatively, the model might not be reproducing local variability in the gravity wave activity and zonal wind profile. The middle panels (Fig. 1d, e and f) in Fig. 1 show the $T, U$ and $V$ composites of major SSW events between 1988 and 2010. To detect major SSW events, we have used the algorithm of de la Torre et al. (2012) and Chandran et al. (2013a). Ten major SSWs between December and February during the period 1988-2010 have been detected using this algorithm. The winters with major SSWs were 1988-1989, 1998-1999, 2000-2001，2001-2002，2002-2003，2003-2004，20052006, 2007-2008, 2008-2009 and 2009-2010. Out of the 10 SSW winters, the 1998-1999, 2003-2004, 2005-2006, 2007-2008 and 2009-2010 SSW winters happened during the easterly phase of the QBO with the others in the westerly 
(a) SD WACCM Climotologicol T (K) DJF 1988-2010

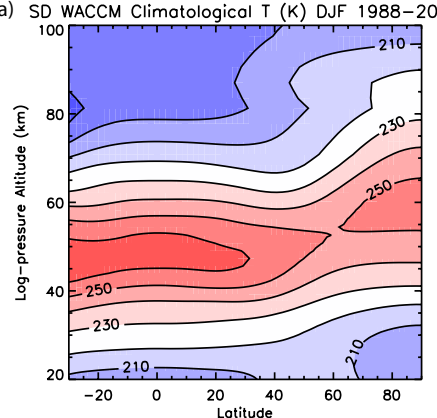

(b)SD WACCM Climatological U (m/s) DJF 1988-2010

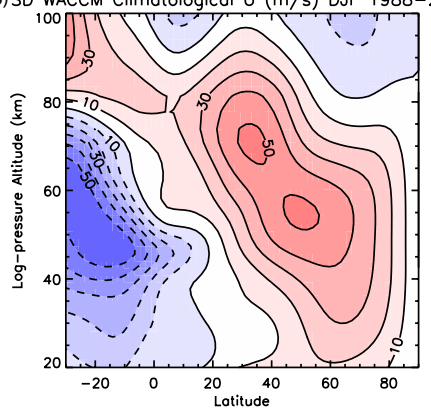

(c) SD WACCM Climatological V (m/s) DJF 1988-2010

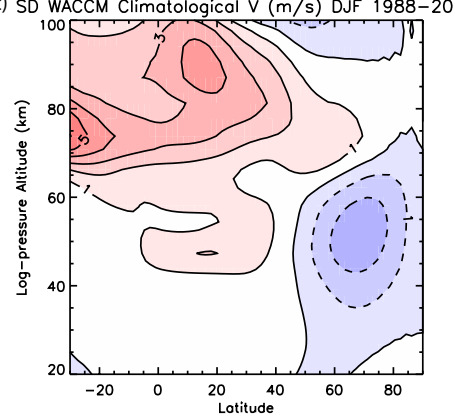

(d) SD WACCM mojor SSW T (K) composite

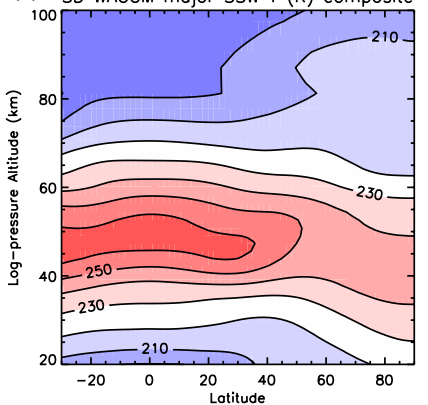

(e) SD WACCM major $\mathrm{SSW} \cup(\mathrm{m} / \mathrm{s})$ composite

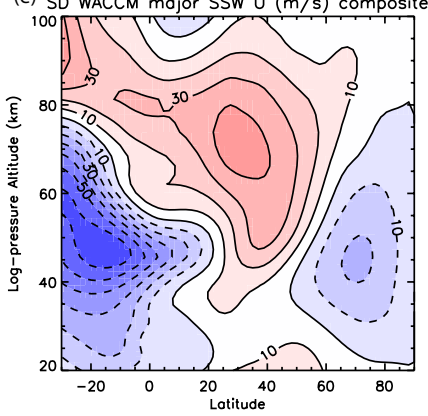

(f) SD WACCM mojor SSW V (m/s) composite

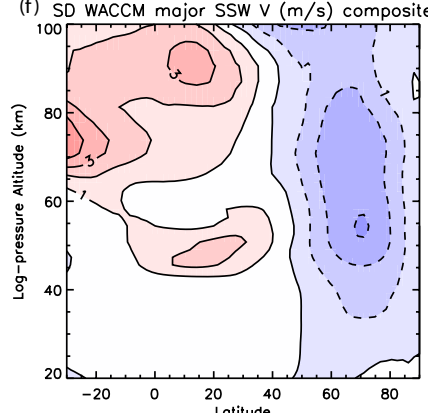

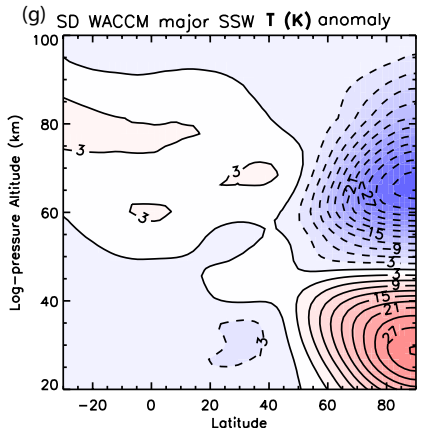

(h) SD WACCM major SSW $\cup(\mathrm{m} / \mathrm{s})$ anomaly

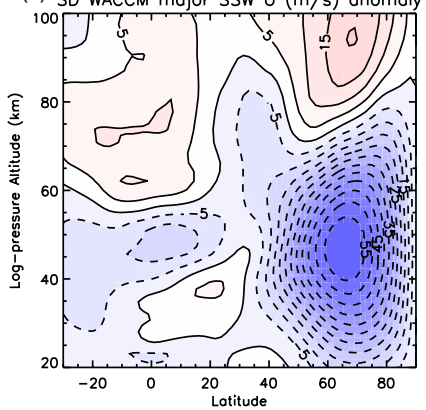

(i) SD WACCM major SSW $v(\mathrm{~m} / \mathrm{s})$ anomaly

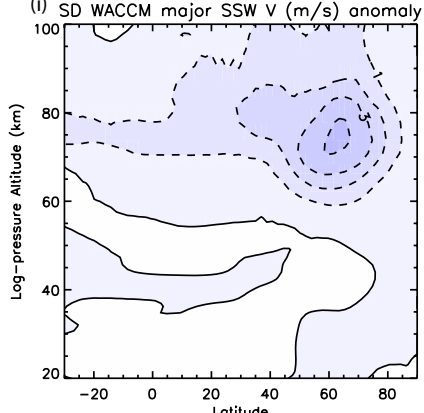

Figure 1. The climatological average zonal-mean (a) temperature $(T),(\mathbf{b})$ zonal wind $(U)$ and $(\mathbf{c})$ meridional wind $(V)$ between December and February from 1988 to 2010, the zonal-mean (d) temperature (e) zonal wind and (f) meridional wind during seven days centered around 10 major SSW events between 1988 and 2010 event and the zonal-mean anomalies from climatological mean during the composite SSW event in (g) temperature (h) zonal wind and (i) meridional wind.

phase of the QBO. To make the composites for zonal-mean temperature and winds, the temperature and wind were averaged for 7 days during the SSW centered on the day of wind reversal at $10 \mathrm{hPa}$ at $60^{\circ} \mathrm{N}$. In Fig. 1d, the lowering of the polar stratopause associated with the SSW can be seen along with a reversal of the high latitude polar zonal-mean jet in Fig. 1e from eastward to westward. The pole-to-pole flow in the mesosphere is disrupted at the time of the SSW and the $\mathrm{NH}$ polar high and middle latitudes show an equatorward meridional wind in Fig. 1f.

Figure $1 \mathrm{~g}, \mathrm{~h}$ and $\mathrm{i}$ show the zonal-mean temperature, zonal-mean zonal wind and zonal-mean meridional wind anomaly during the SSW calculated as the difference between the zonal-mean temperature and winds during the SSW from the climatological mean values. In the high latitude regions (poleward of $60^{\circ} \mathrm{N}$ ), the anomalous stratospheric warming and mesospheric cooling can be clearly seen in Fig. 1g. The stratospheric warming (caused by breaking planetary waves) and mesospheric cooling (caused by reversal in gravity wave forcing in the mesosphere) reach peak values of $\sim 30 \mathrm{~K}$ in these composite plots. For individual years, the magnitudes can be even larger. In the middle and low latitudes in the stratosphere there is generally a cooling and in the mesosphere there is generally a warming. In the composite plots the maximum magnitudes of warming and cooling are less than $3 \mathrm{~K}$. These alternating warming and cooling cells in the stratosphere and mesosphere are a robust feature associated with branches of the residual circulation changes that are driven by breaking planetary wand gravity waves (Chandran et al., 2014). The zonal-mean wind anomaly plot of Fig. 1h shows large westward wind reversal in the stratosphere poleward of $40^{\circ} \mathrm{N}$. In the upper MLT there is a net eastward acceleration of the zonal-mean wind caused by enhanced penetration of eastward gravity waves into this 

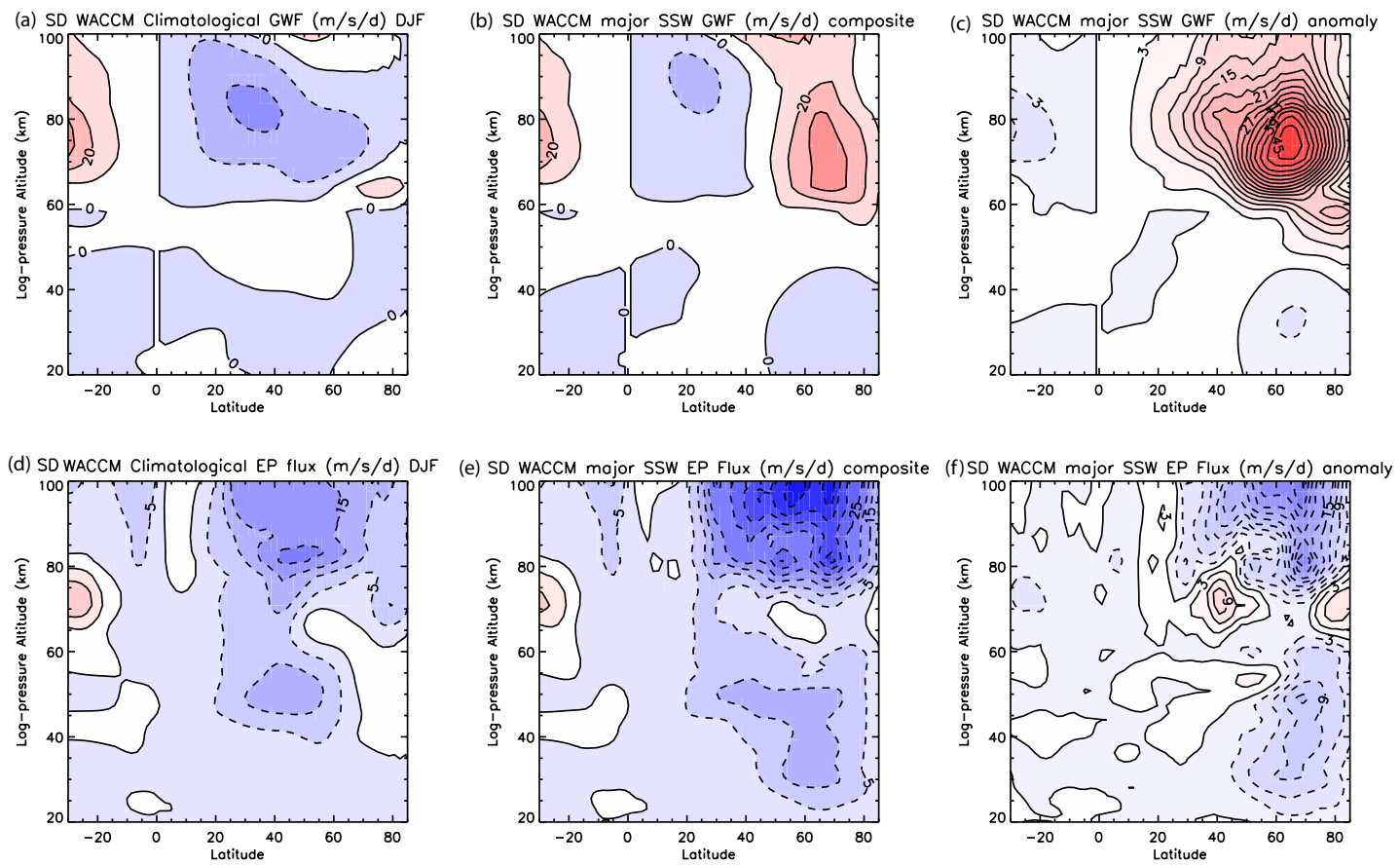

Figure 2. The climatological average zonal-mean gravity wave forcing (top) and Eliassen-Palm flux (bottom panels), respectively, (a, d) between December and February from 1988 to 2010, (b, e) during seven days centered around 10 major SSW events between 1988 and 2010 and $(\mathbf{c}, \mathbf{f})$ Gravity wave forcing anomaly calculated as difference during the composite SSW event from the climatological mean.

region. The mesospheric wind, which is normally westward in winter in mid-high latitudes, reverses to eastward during SSW events. Another interesting feature during SSW is the deceleration of the eastward zonal-mean zonal wind between 20 and $40^{\circ} \mathrm{N}$ in the mesosphere. Below $40 \mathrm{~km}$ in the low latitudes (between 0 and $20^{\circ} \mathrm{N}$ ), there is an eastward acceleration of the zonal-mean flow, while above that region (between 40 and $60 \mathrm{~km}$ ) there is a westward acceleration of the zonal-mean flow and eastward acceleration between 60 and $100 \mathrm{~km}$. The southern hemispheric low latitudes experience a net westward forcing (with $\sim$ peak values of $10 \mathrm{~m} \mathrm{~s}^{-1}$ ) of the zonal-mean flow between 40 and $70 \mathrm{~km}$ and an eastward forcing in the mesosphere $(60-100 \mathrm{~km})$, with peak values between 5 and $10 \mathrm{~m} \mathrm{~s}^{-1}$. The meridional wind anomaly shown in Fig. 1h shows a deceleration of the middle atmosphere pole-to-pole flow in the Northern Hemisphere and in southern hemispheric low latitudes. The meridional circulation reverses in the northern hemispheric high latitudes and becomes equatorward driven by the gravity wave upwelling there.

In Fig. 2, we show the climatological gravity wave forcing (GWF) in the model averaged over December, January and February (Fig. 2a), the GWF during SSW events (Fig. 2b) and the GWF anomaly at the time of SSW events (Fig. 2c). In the bottom panels, we show the climatological EP flux in the model averaged over December, January and February (Fig. 2d), the EP flux during SSW events (Fig. 2e) and the EP flux anomaly at the time of SSW events (Fig. 2f).
The climatological GWF in the Northern Hemisphere in winter is westward in the MLT (reaching maximum values of $\sim 30 \mathrm{~m} \mathrm{~s}^{-1} \mathrm{~d}^{-1}$ ) since the eastward stratospheric zonalmean wind filters out the eastward waves while allowing the westward gravity waves to propagate up in to the mesosphere. Conversely, the GWF in the Southern Hemisphere is eastward in the MLT due to filtering of westward gravity waves by the eastward stratospheric zonal-mean wind. At the time of the SSW, the reversal of the zonal-mean wind from eastward to westward in the high and mid-latitudes now filters out the westward gravity waves while allowing the eastward gravity waves to propagate into the mesosphere; as a consequence, the GWF in the mesosphere poleward of $40^{\circ} \mathrm{N}$ becomes eastward, reaching maximum values of $\sim 30 \mathrm{~m} \mathrm{~s}^{-1} \mathrm{~d}^{-1}$ in the opposite direction, as can be seen in Fig. 2b. The GWF anomaly shown in Fig. $2 c$ is eastward at all latitudes above $10^{\circ} \mathrm{N}$, which can be attributed to the enhanced westward acceleration in the zonal wind anomaly shown in Fig. 1h, which filters out more of the westward gravity waves. In the bottom panels from Fig. $2 d$ and e, the EP flux shows enhanced values at the time of the SSW in both the lower stratosphere $\left(\sim 10 \mathrm{~m} \mathrm{~s}^{-1} \mathrm{~d}^{-1}\right.$ below $\left.45 \mathrm{~km}\right)$ and MLT $\left(\sim 45 \mathrm{~m} \mathrm{~s}^{-1} \mathrm{~d}^{-1}\right)$ compared to climatological values of $\sim 0-5 \mathrm{~m} \mathrm{~s}^{-1} \mathrm{~d}^{-1}$ below $45 \mathrm{~km}$ and $\sim 15 \mathrm{~m} \mathrm{~s}^{-1} \mathrm{~d}^{-1}$ in the MLT . This is due to the enhanced planetary wave activity, which causes the SSW. At the time of the SSW, the enhanced EP flux in the MLT may in part be due to in situ 

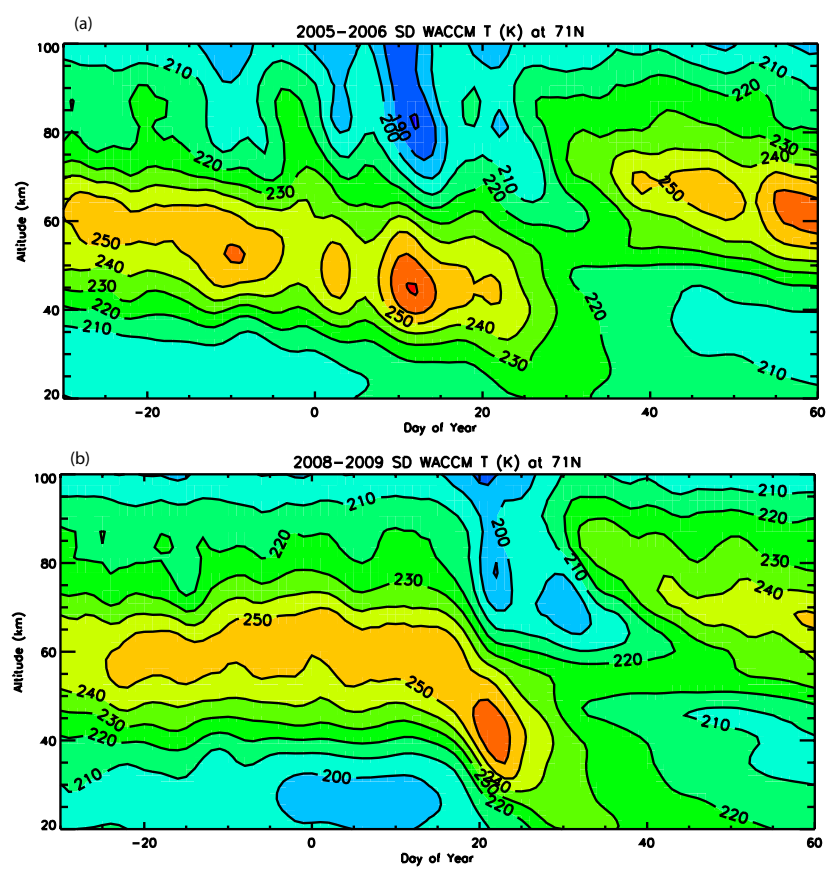

Figure 3. The zonal-mean temperature at $71^{\circ} \mathrm{N}$ from December to February end with day of year (DOY) 0 representing 1 January, during (a) the Arctic winter of 2005-2006 and (b) 2008-2009.

generation of planetary waves in the upper stratosphere and mesosphere (Chandran et al., 2013b).

\subsection{Case studies of different types of SSW during 2006 and 2009}

In Fig. 3 we show the zonal-mean temperature at $71^{\circ} \mathrm{N}$ from December to February, with day of year (DOY) 0 representing 1 January, during the Arctic winter of 2005-2006 (Fig. 3a) and during 2008-2009 (Fig. 3b). These two Arctic winters were characterized by strong SSW events, in January 2006 and January 2009, followed by the formation of elevated stratopause events. Both the 2006 and 2009 SSWs have been studied in great detail (e.g., Manney et al., 2008, 2009; McLandress et al., 2013). While the 2006 SSW was characterized by a vortex displacement, the 2009 SSW was a vortex splitting event. The 2006 event occurred during the easterly phase of the QBO while the 2009 event occurred during the westerly phase of the QBO. In this study we use these two events as case studies to explore the effect of SSW events on mid- and low latitude temperature and winds during the different phases of the QBO.

The peak of the 2006 SSW occurred between 9 and 14 January (DOY 8-13) and the peak of the 2009 SSW between 19 and 24 January (DOY 18-23). Manney et al. (2008, 2009) and McLandress et al. (2013) discuss the 2006 and 2009 SSW events. In Figs. 4 and 5, we show the zonal-mean temperature, zonal-mean wind and meridional mean wind as a seasonal average (December to February) in panels a, b and $\mathrm{c}$, averaged during the SSW event in panels d, e and f, and the zonal-mean anomalies in temperature, zonal wind and meridional wind calculated as difference between the SSW values from the seasonal mean in panels $\mathrm{g}, \mathrm{h}$ and $\mathrm{i}$. The seasonal average (from 1 December to 28 February) of zonal-mean temperature, zonal wind and meridional winds (panels a, b and c in Figs. 4 and 5) during 2005-2006 and 2008-2009 are generally similar to the climatological zonal-mean temperature shown in Fig. 1a, b and c. However, there are some significant differences in the zonal wind in 2005-2006. The zonal-mean zonal wind in Fig. 4b for 2005-2006 shows differences from the climatology plot shown in Fig. 1b at low latitudes (between 0 and $20^{\circ} \mathrm{N}$ ) in the Northern Hemisphere below $30 \mathrm{~km}$, where it is westward indicating it is the easterly phase of the QBO. Above that at low latitudes from 30 to $40 \mathrm{~km}$, the wind is eastward. In Fig. 5 b, the zonal-mean zonal wind is eastward at $20 \mathrm{~km}$ at the equator, indicating it is the westerly phase of the QBO. The zonal-mean wind above this region is westward in the low latitudes. The stratospheric winds in the tropics during the easterly phase of the QBO are weaker than during the westerly phase (Baldwin and Dunkerton, 2001) and hence the climatological plots show tropical stratospheric wind structure similar to the westerly phase of the QBO.

During the SSW period, averaged between 9 and 14 January in 2006 and 19 and 24 January in 2009, the zonal-mean temperature (Figs. $4 \mathrm{~d}$ and $5 \mathrm{~d}$ ) shows the warming and descent of the polar stratopause and the mesospheric cooling above; the zonal winds (Figs. 4e and 5e) show reversal of the zonal-mean flow at latitudes poleward of $40^{\circ} \mathrm{N}$. In 2009, during the westerly phase of the QBO, when the zonal wind in the low latitude $\left(0-20^{\circ} \mathrm{N}\right)$ stratosphere is westward, the wind reversal during the SSW at mid- and high latitudes links with the low latitude westward wind and results in a band of westward wind in the stratosphere from the equator to the pole. The meridional wind (Figs. 4f and 5f) shows considerable equatorward flow poleward of $40^{\circ} \mathrm{N}$ in the MLT. In the low latitude $\left(10^{\circ} \mathrm{S}\right.$ to $\left.40^{\circ} \mathrm{N}\right)$ stratosphere breaking planetary waves enhance the poleward flow.

During both SSW events, the temperature anomaly plot (Figs. $4 \mathrm{~g}$ and $5 \mathrm{~g}$ ) shows the stratospheric warming below $60 \mathrm{~km}$ and poleward of $40^{\circ} \mathrm{N}$ which reaches peak values of $\sim 40 \mathrm{~K}$. The mesospheric cooling at these latitudes also shows peak magnitudes of $\sim 45 \mathrm{~K}$. In the stratosphere below $60 \mathrm{~km}$, at low and mid-latitudes there is a cooling with peak magnitudes of $\sim 6 \mathrm{~K}$ at the equator at $\sim 50 \mathrm{~km}$. The cooling region extends into the southern hemispheric low latitudes as well. In the low and mid-latitude mesosphere there is a warming with peak values of $\sim 6 \mathrm{~K}$ at $30^{\circ} \mathrm{N}$ between 70 and $75 \mathrm{~km}$. This anomaly extends into the lower latitudes in the Southern Hemisphere in the $60-90 \mathrm{~km}$ altitude range.

The zonal wind anomaly with respect to the seasonal mean shown in Figs. 4h and 5h shows patterns similar to the composite zonal wind anomaly shown in Fig. 1h. In the Northern Hemisphere, poleward of $40^{\circ} \mathrm{N}$ in the upper stratosphere and 
(a) DJF average zonal mean $\mathrm{T}(\mathrm{K})$ for 2005-2006

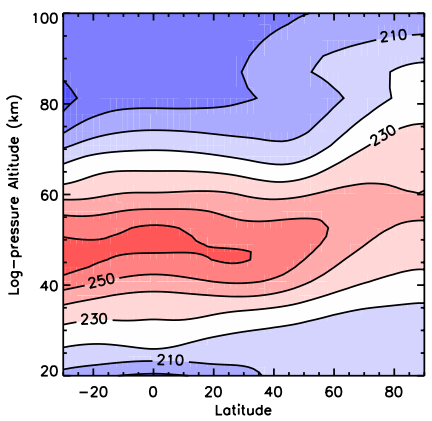

(b) DJF average zonal mean U(m/s) for 2005-2006

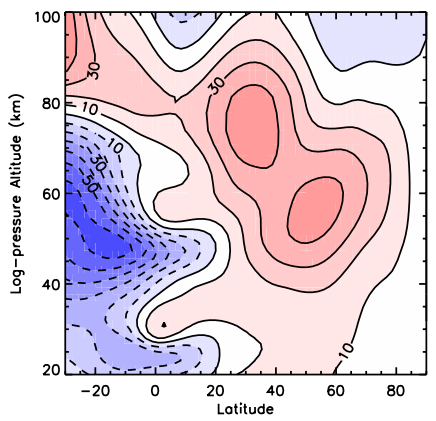

(c) DJF average zonal mean $\mathrm{V}(\mathrm{m} / \mathrm{s})$ for 2005-2006

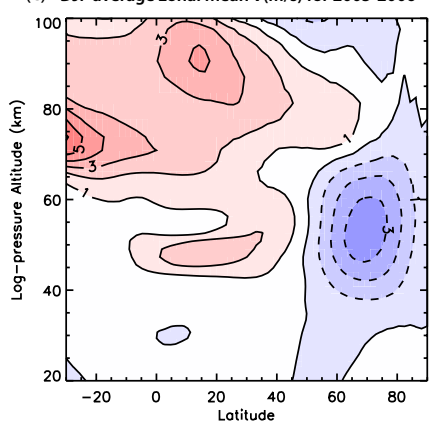

(d) Zonal mean T (K), January 9-14, 2006

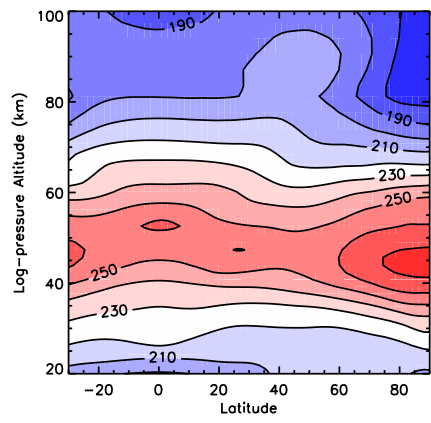

(e) Zonal mean U(m/s), January 9-14, 2006

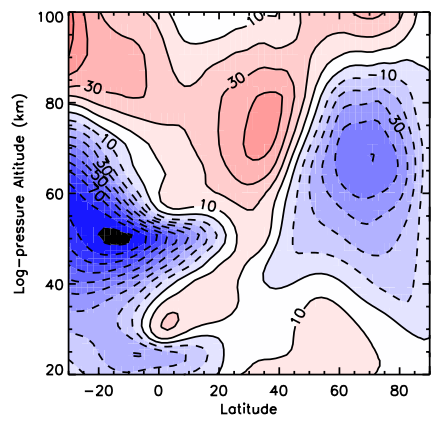

(f) Zonal mean $\mathrm{V}(\mathrm{m} / \mathrm{s})$, January 9-14, 2006

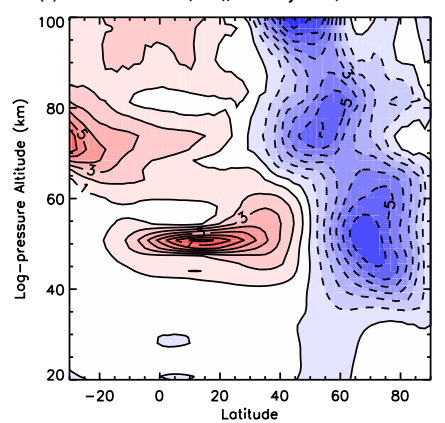

(g) Zonal mean T (K) anomaly, January 9-14 2006

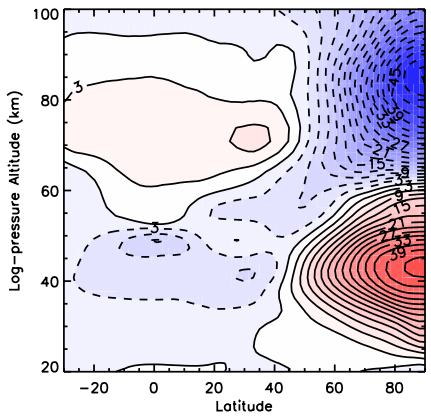

(h) Zonal mean U (m/s) anomaly, January 9-14 2006

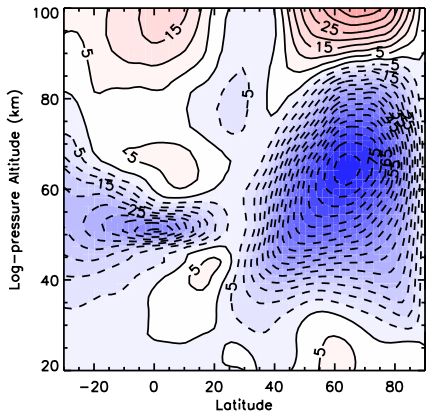

(i) Zonal mean $\mathrm{V}(\mathrm{m} / \mathrm{s})$ anomaly, January 9-14 2006

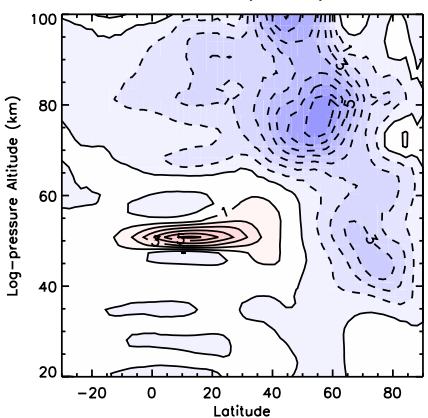

Figure 4. The seasonal average zonal-mean (a) temperature $(T)$, (b) zonal wind $(U)$ and (c) meridional wind $(V)$ between December and February during the winter of 2005-2006, the zonal-mean (d) temperature (e) zonal wind and (f) meridional wind during 9-14 January days centered around 2006 SSW event and the zonal-mean anomalies as difference from climatological mean during the SSW event in (g) temperature (h) zonal wind and (i) meridional wind.

lower mesosphere (between 30 and $85 \mathrm{~km}$ ), there is a westward anomaly in the zonal wind. In the upper MLT there is an eastward anomaly. Between 20 and $40^{\circ} \mathrm{N}$, there is a westward anomaly (or deceleration) of the eastward zonal-mean flow (at peak values of $\sim 5 \mathrm{~m} \mathrm{~s}^{-1}$ in 2006 and $\sim 20 \mathrm{~m} \mathrm{~s}^{-1}$ in 2009). In the lower latitudes (between 0 and $20^{\circ} \mathrm{N}$ ), there is an eastward anomaly below $40 \mathrm{~km}$, westward anomaly between 40 and $60 \mathrm{~km}$ and eastward anomaly between 60 and $100 \mathrm{~km}$ altitudes. The southern hemispheric low latitudes shows a westward anomaly (with peak values of $\sim 25 \mathrm{~m} \mathrm{~s}^{-1}$ ) in the zonal-mean flow between 40 and $70 \mathrm{~km}$ and an eastward anomaly of the zonal-mean flow in the mesosphere $(60-100 \mathrm{~km})$ with peak values between 5 and $10 \mathrm{~m} \mathrm{~s}^{-1}$. The meridional wind anomaly during the SSW events (Figs. 4h and $5 \mathrm{~h}$ ) shows the equatorward flow in the MLT which reaches peak values of $7 \mathrm{~m} \mathrm{~s}^{-1}$ at $50^{\circ} \mathrm{N}$ in 2006 and $9 \mathrm{~m} \mathrm{~s}^{-1}$ at $\sim 40^{\circ} \mathrm{N}$ in 2009 . This equatorward anomaly extends to the low latitude MLT region and acts to decelerate the pole-topole flow in the tropics. The low latitude stratosphere shows a poleward flow (between $10^{\circ} \mathrm{S}$ to $40^{\circ} \mathrm{N}$ ) driven by the breaking planetary waves.

\subsection{Planetary wave propagation during 2006 and 2009 SSWs}

To investigate the propagation of planetary waves and the net EP flux divergences before and during the 2006 and 2009 SSW events, we examine the behavior of the quantity $\cos ^{2} \theta F$, where $F$ is the zonal-mean zonal acceleration due to wave growth or dissipation. The actual EP flux vector, 
(a) DJF average zonal mean T(K) for 2008-2009

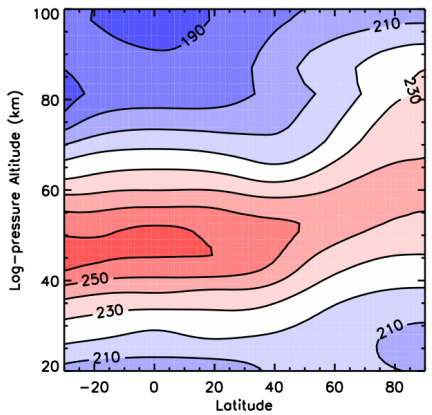

(b) DJF average zonal mean $\mathrm{U}(\mathrm{m} / \mathrm{s})$ for 2008-2009

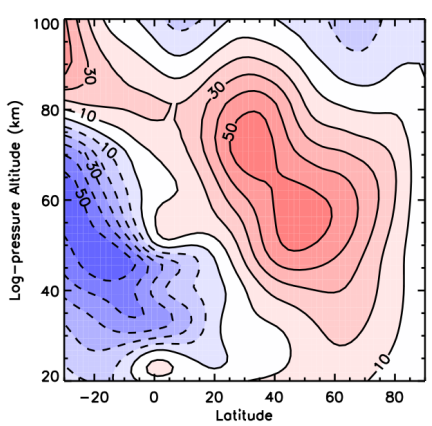

(c) DJF average zonal mean V(m/s) for 2008-2009

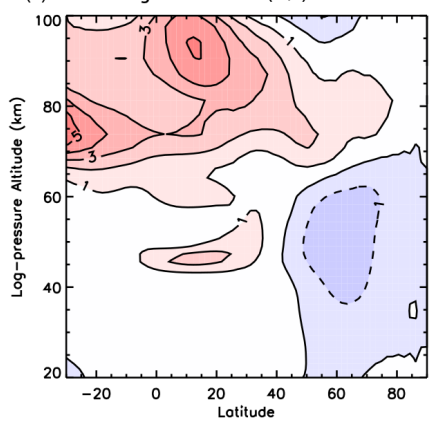

(d) Zonal mean T (K), January 19-24, 2009

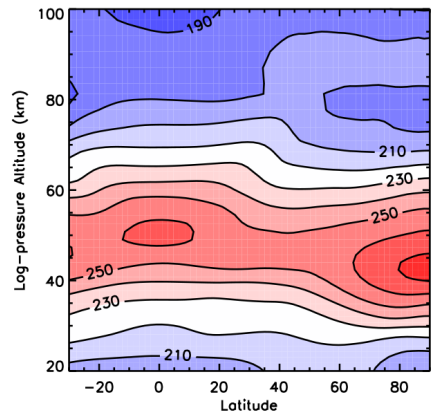

(e) Zonal mean $\mathrm{U}(\mathrm{m} / \mathrm{s})$, January 19-24, 2009

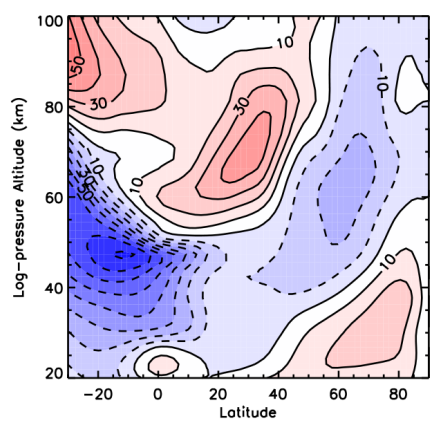

(f) Zonal mean V(m/s), January 19-24, 2009

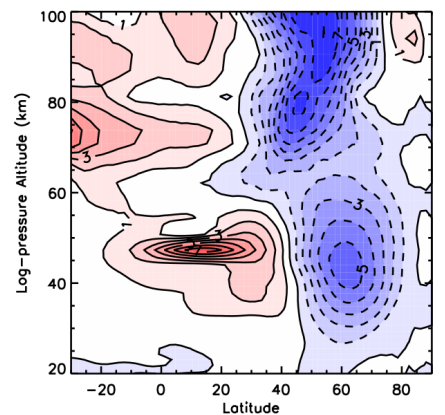

(g) Zonal mean T (K) anomaly, January 19-24 2009

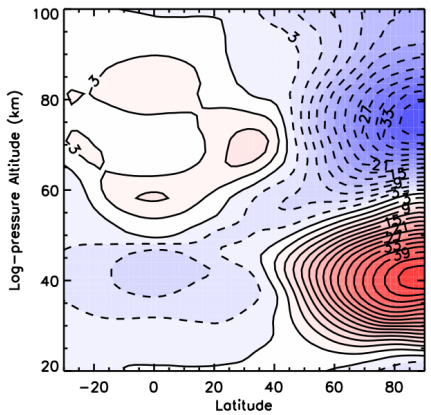

(h) Zonal mean U (m/s) anomaly, January 19-24 2009

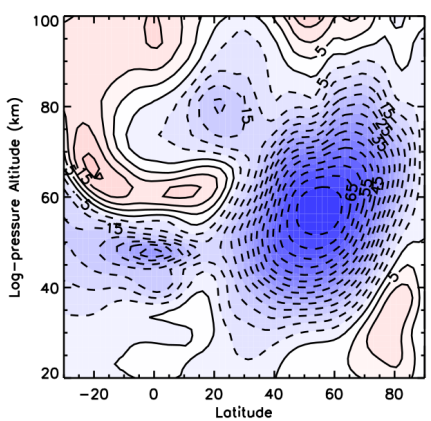

(i) Zonal mean V (m/s) anomaly, January 19-24 2009

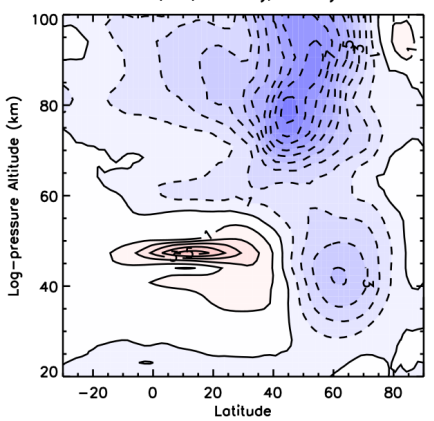

Figure 5. The seasonal average zonal-mean (a) temperature $(T),(\mathbf{b})$ zonal wind $(U)$ and (c) meridional wind $(V)$ between December and February during the winter of 2008-2009, the zonal-mean (d) temperature (e) zonal wind and (f) meridional wind during 19-24 January days centered around 2009 SSW event and the zonal-mean anomalies as difference from climatological mean during the SSW event in (g) temperature (h) zonal wind and (i) meridional wind.

$\boldsymbol{F}$, cannot in practice be plotted over a deep layer of the atmosphere because it varies by several orders of magnitude between the stratosphere and the MLT. Following Chandran et al. (2013b), $\boldsymbol{F}^{\prime}$ is a wave activity flux vector, akin to the EP flux. The contours of $\cos ^{2} \theta F$ will be consistent with the apparent convergence/divergence of $\boldsymbol{F}^{\prime}$ in the Cartesian coordinate system $(a \theta, z) . \boldsymbol{F}^{\prime}$ can be viewed as a tool to visualize qualitatively the propagation and dissipation of wave activity flux over an extended altitude range (Chandran et al., 2013b).

Figure 6 shows $\boldsymbol{F}^{\prime}$ vectors superimposed on contours of $\cos ^{2} \theta F$, both averaged over 5-14 January, 2006 (Fig. 6a) and 15-24 January, 2009 (Fig. 6c). This period encompasses the time during which the planetary wave activity reaches its maximum values. The plots on the right (Fig. 6b and d) highlight the propagation of wave vectors in the low latitude stratosphere, since the wave activity is much weaker in this region and cannot be clearly seen when plotting over the whole latitude range. The zonal-mean zonal wind is plotted as black contours (at $10 \mathrm{~m} \mathrm{~s}^{-1}$ intervals); the red contours indicate the zero wind line. The regions of positive EP flux (red color contours) indicate regions of EP flux divergence or regions of wave sources and the blue regions indicate regions of EP flux convergence or regions of planetary wave breaking. In both the SSW events, it can be seen that the planetary wave activity causing the SSW originates mostly in the mid-high latitudes. The waves propagate vertically upward and equatorward breaking between 40 and $60 \mathrm{~km}$, mostly between 30 and $70^{\circ} \mathrm{N}$, causing the reversal of the stratospheric zonal-mean flow. The $\boldsymbol{F}^{\prime}$ vectors also indicate propagation to the mid-latitude (between 20 and $60^{\circ} \mathrm{N}$ ) MLT region, along 

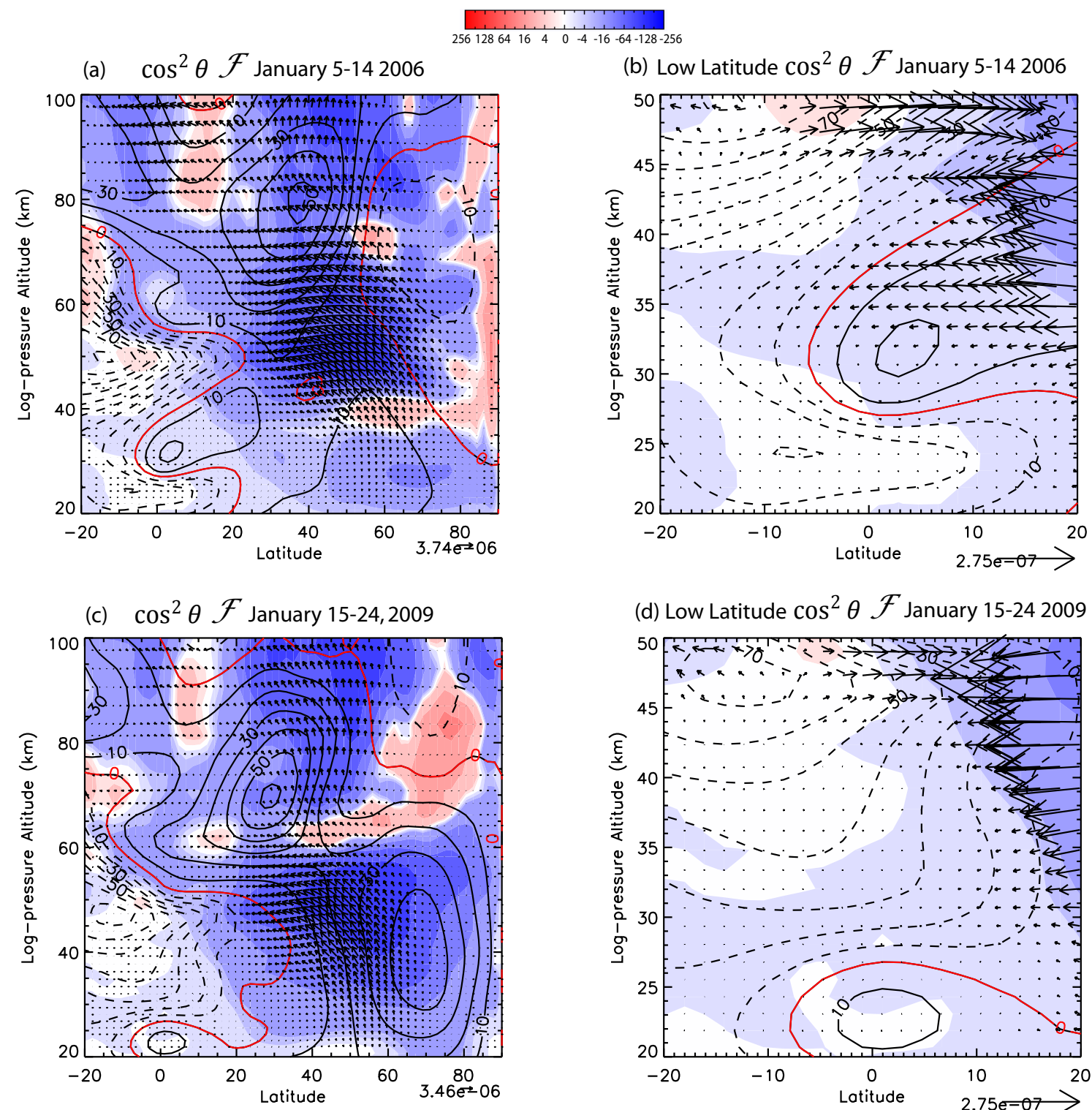

(d) Low Latitude $\cos ^{2} \theta \mathcal{F}$ January 15-24 2009

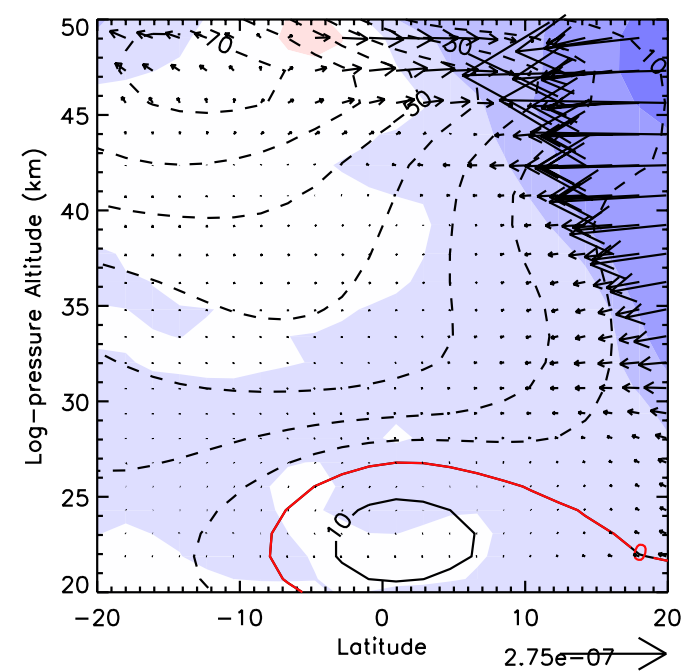

Figure 6. Plot of $\boldsymbol{F}^{\prime}$ vectors superimposed on contours of $\cos ^{2} \theta F$, (a) between 20 and $100 \mathrm{~km}$ and $20^{\circ} \mathrm{S}$ to $90^{\circ} \mathrm{N}$ averaged over $5-$ 14 January 2006, (b) between 20 and $50 \mathrm{~km}$ and $20^{\circ} \mathrm{S}$ to $20^{\circ} \mathrm{N}$ averaged over 5-14 January 2006, (c) between 20 and $100 \mathrm{~km}$ and $20^{\circ} \mathrm{S}$ to $90^{\circ} \mathrm{N}$ averaged over 15-24 January 2009 and (d) between 20 and $50 \mathrm{~km}$ and $20^{\circ} \mathrm{S}$ to $20^{\circ} \mathrm{N}$ averaged over $15-24$ January 2009 . The zonal-mean zonal wind is plotted as black contours (at $10 \mathrm{~m} \mathrm{~s}^{-1}$ intervals); the red contours indicate the zero wind line.

the eastward winds prevailing in this region. It needs to be investigated whether these are secondary waves generated in the middle atmosphere following reversals in the zonalmean winds similar to the secondary planetary waves shown in Chandran et al. (2013b).

During 2006, which is in the easterly phase of the QBO, the wind is eastward in the low latitudes between 30 and $45 \mathrm{~km}$ and this enables the planetary waves to propagate across the equator at this altitude (Fig. 6b). In 2009, which is in the westerly phase of the QBO, the westward wind in this region causes the planetary waves to break near the zero wind line which is at $25-30^{\circ} \mathrm{N}$ and hence there is no planetary wave activity in the equator (Fig. 6d). The planetary wave driven westward acceleration of the zonal-mean flow reaches peak values of $\sim 5$ to $10 \mathrm{~m} \mathrm{~s}^{-1}$ day $^{-1}$ at altitudes as low as $\sim 35 \mathrm{~km}$ in the easterly phase of the QBO and $\sim 30 \mathrm{~km}$ in the westerly phase of the QBO. The propagation of planetary waves across the equator during the easterly phase of the QBO is consistent with studies from Ortland (1997) who showed a similar pattern of planetary wave propagation in November of 1994 during the easterly phase of the QBO. The propagation of planetary waves across the tropics also 
(a) Residual Circulation January 5-14 2006

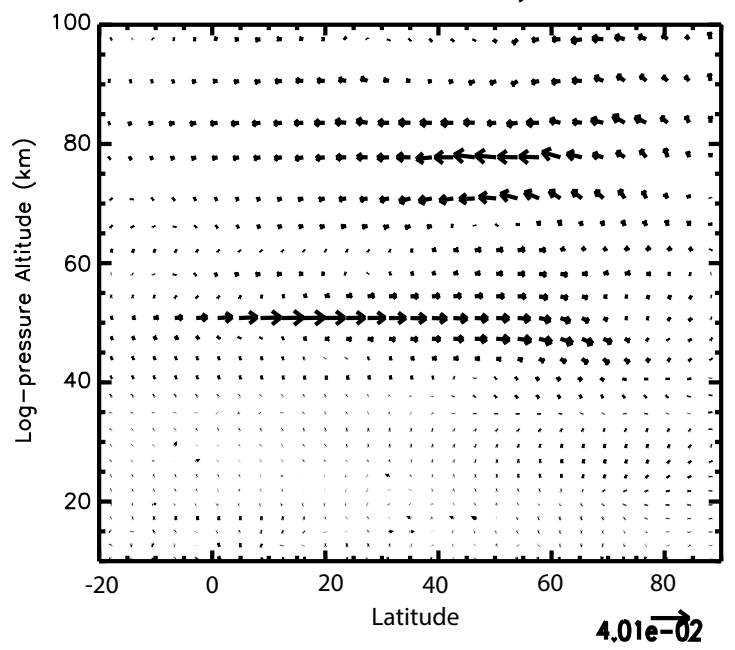

(c) Residual Circulation January 15-24, 2009

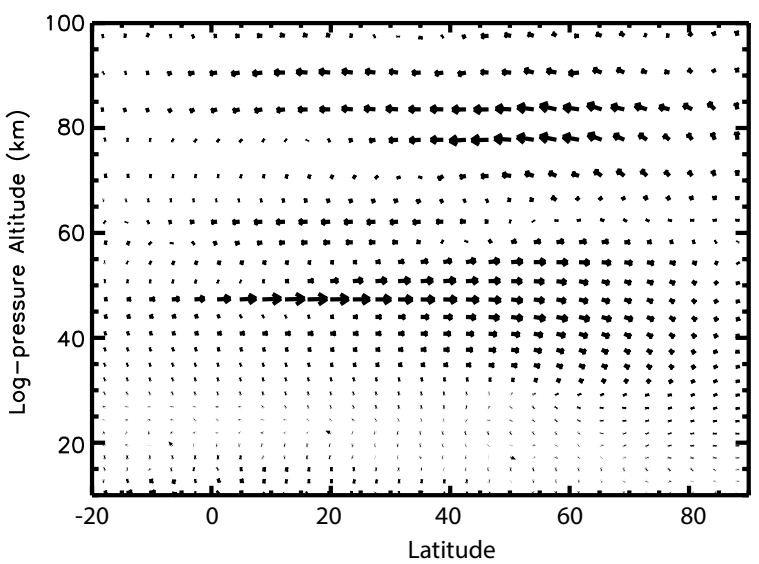

(b) Low Latitude residual circulation January 5-14 2006

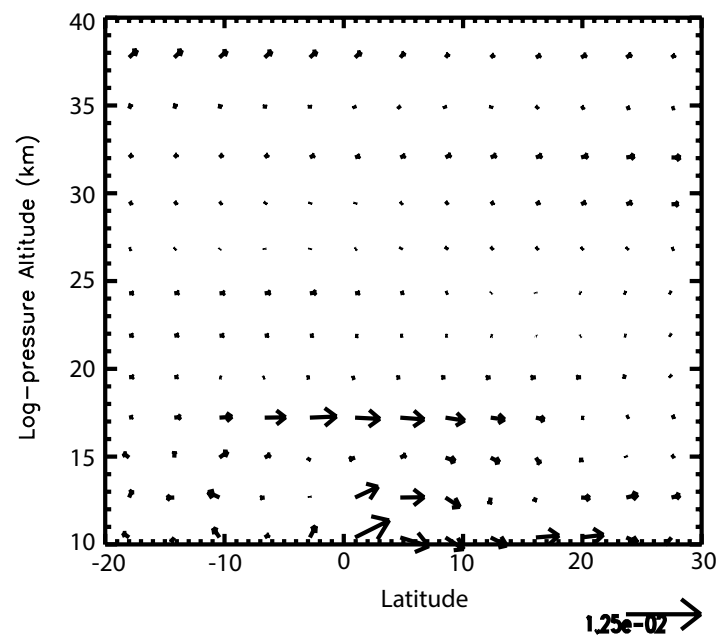

(d) Low Latitude residual circulation January 15-24 2009

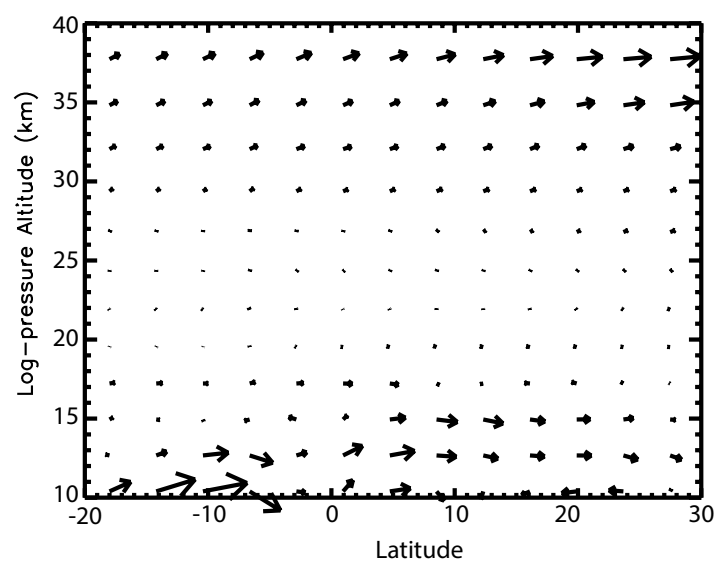

Figure 7. Plot of residual circulation vectors (a) between 10 and $100 \mathrm{~km}$ and $20^{\circ} \mathrm{S}$ to $90^{\circ} \mathrm{N}$ averaged over 5-14 January 2006 , (b) between 10 and $40 \mathrm{~km}$ and $20^{\circ} \mathrm{S}$ to $30^{\circ} \mathrm{N}$ averaged over 5-14 January 2006, (c) between 10 and $100 \mathrm{~km}$ and $20^{\circ} \mathrm{S}$ to $90^{\circ} \mathrm{N}$ averaged over $15-$ 24 January 2009 and (d) between 20 and $50 \mathrm{~km}$ and $20^{\circ} \mathrm{S}$ to $30^{\circ} \mathrm{N}$ averaged over 15-24 January 2009.

has implications for constituent exchange between the extratropics and tropics (O'Sullivan, 1997) and in contributing to the momentum budget of the QBO in the upper stratosphere (Dunkerton, 1983).

In Fig. 7, we show the residual circulation vectors in 2006 (averaged between 5 and 14 January) and 2009 (averaged between 15 and 24 January) in Fig. 7a and c, respectively. The residual circulation in the tropics and extra-tropics during the same period are shown in detail in Fig. $7 \mathrm{~b}$ and d. The residual circulation plots in Fig. 7a and c show the enhanced poleward flow in the stratosphere in the low and mid-latitudes and downwelling over the poles leading to the stratospheric warming. It also clearly shows the upwelling in the mesosphere over the poles leading to the mesospheric cooling and the resulting equatorward flow in the MLT. In the tropical stratosphere, during the easterly phase of the QBO in 2006, the upwelling over the tropics and poleward flow in the stratosphere (between 30 and $40 \mathrm{~km}$ ) is much weaker compared to 2009. During the easterly phase of the QBO, the peak upwelling and poleward flow occur in the lower stratosphere (between 10 and $20 \mathrm{~km}$ ). The penetration of westward planetary waves across the equator in the upper stratosphere during the easterly phase of the QBO as shown in Fig. 6 reduces the upwelling and poleward flow resulting in less cooling of the tropical upper stratosphere. In the westerly phase of the QBO, since the planetary waves do not penetrate into the tropics, the upwelling and poleward flow is much stronger between 30 and $40 \mathrm{~km}$.

\subsection{Variability during the 2006 and 2009 SSWs}

While the zonal-mean diagnostics shown previously can provide useful information on temperature and wind changes in the high, mid- and low latitude regions, very often observations at the same latitudes show variability in terms of the observed temperature and winds. In Fig. 8 we show 


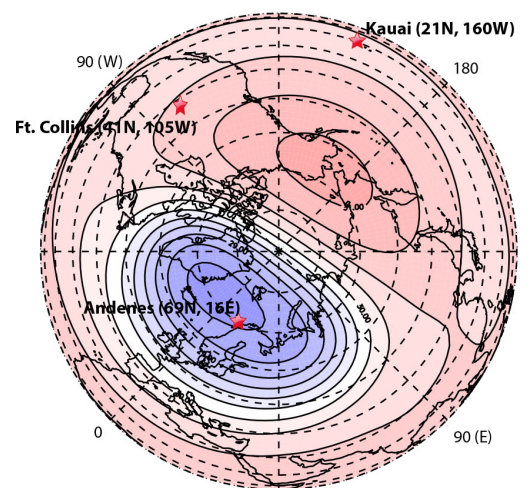

Geopotential height $(\mathrm{km})$ at $3 \mathrm{hPa}(\sim 40 \mathrm{~km})$ January 9-14, 2006

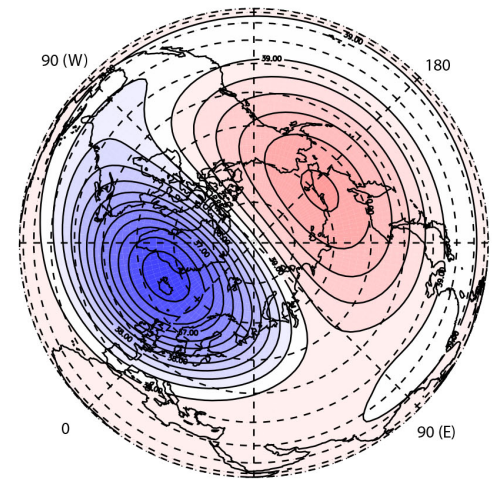

Geopotential height $(\mathrm{km})$ at $1 \mathrm{hPa}(\sim 48 \mathrm{~km})$ January 9-14, 2006

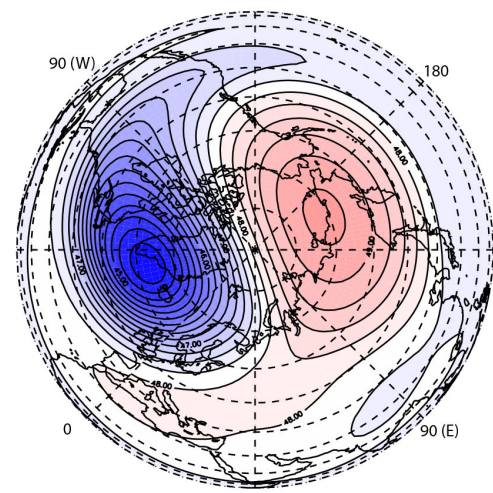

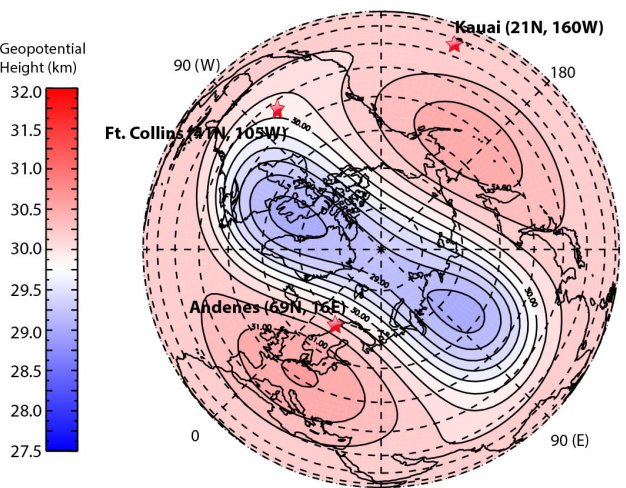

Geopotential height $(\mathrm{km})$ at $3 \mathrm{hPa}(\sim 40 \mathrm{~km})$ January 19-24, 2009

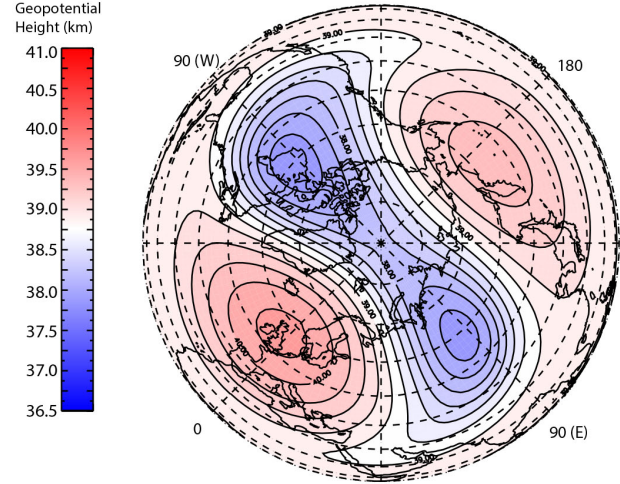

Geopotential height $(\mathrm{km})$ at $1 \mathrm{hPa}(\sim 48 \mathrm{~km})$ January 19-24, 2009

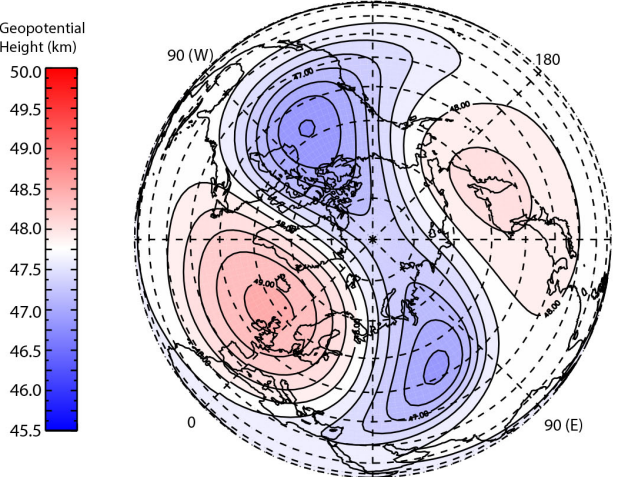

Figure 8. The geopotential height during 2006 SSW event (left panels) and 2009 SSW event (right panel) averaged between 9 and 14 January at (top panel) $10 \mathrm{hPa}(\sim 32 \mathrm{~km})$, (middle panel) $3 \mathrm{hPa}(\sim 40 \mathrm{~km})$ and (bottom panel) $1 \mathrm{hPa}(\sim 48 \mathrm{~km})$. The red star in Fig. 7a indicates locations for which temperature and mean winds are shown in Fig. 8.

the geopotential height at $10 \mathrm{hPa}(\sim 32 \mathrm{~km}), 3 \mathrm{hPa}(\sim 40 \mathrm{~km})$ and $1 \mathrm{hPa}(\sim 48 \mathrm{~km})$ in the top, middle and bottom panels averaged between 9 and 14 January 2006 (left panels) and between 19 and 24 January 2009 (right panels). From the geopotential height perturbations it can be ascertained that the 2006 event is a vortex displacement event while the 2009 event is a vortex splitting event. The planetary wave activity leading to the SSW in 2006 is planetary wave 1 (PW1), while in 2009 the triggering planetary wave activity for the SSW is planetary wave 2 (PW2). During the 2006 event (left panels), the vortex is displaced over Europe and the Atlantic between $90^{\circ} \mathrm{W}$ and $90^{\circ} \mathrm{E}$ while there is an anticyclone over western North America and most of Asia and the Pacific. This anticyclone drives the SSW and the peak downwelling over the stratosphere and upwelling in the mesosphere is occurring over the anticyclone sectors (between $65-70^{\circ} \mathrm{N}$ over the 
2005/2006 Winter
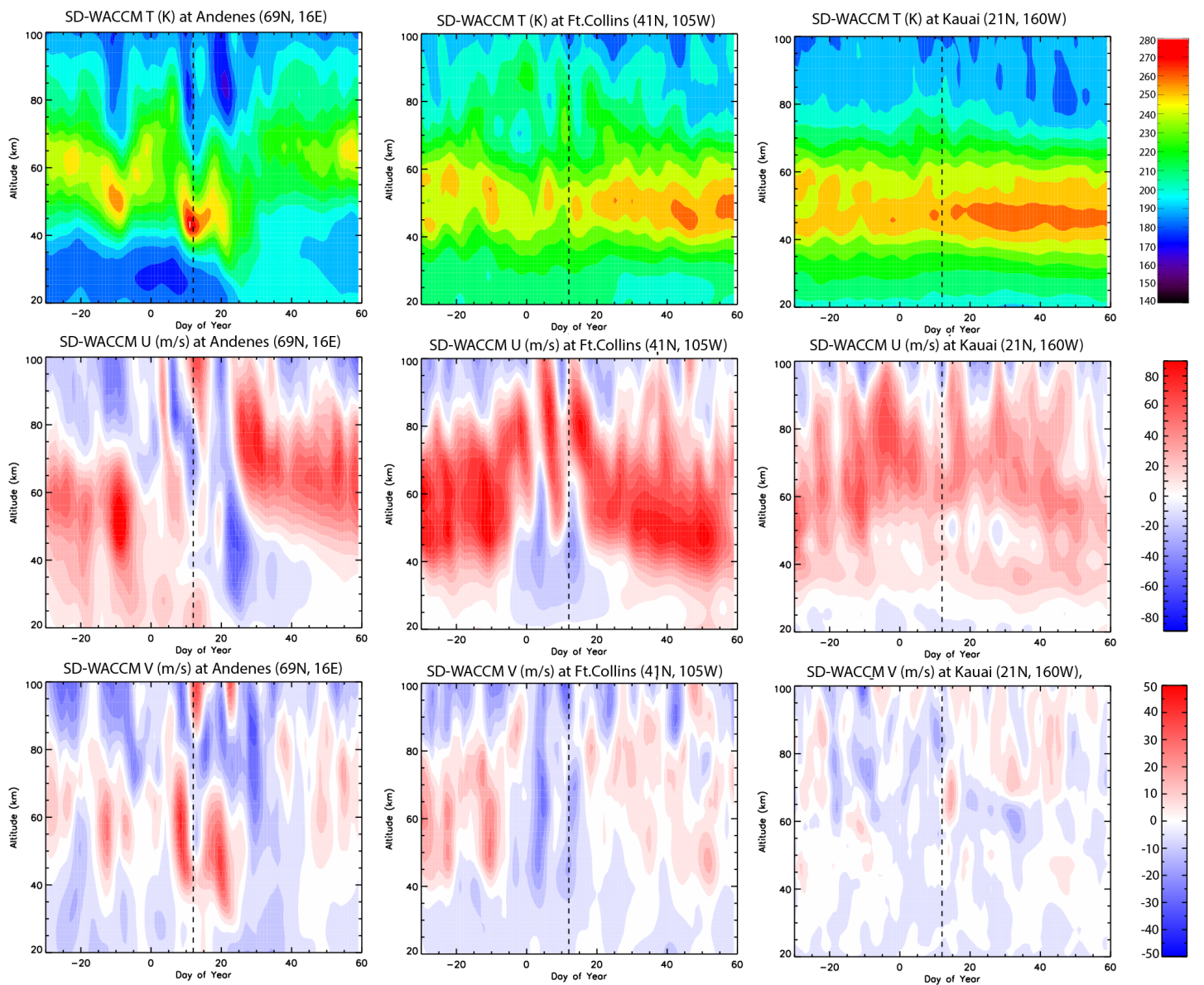

Figure 9. The temperature (top panel), zonal-mean zonal wind (middle panel) and mean meridional wind (bottom panel) from the WACCM at grid points closest to Andenes $\left(69^{\circ} \mathrm{N}, 16^{\circ} \mathrm{E}\right)$, Fort Collins $\left(41^{\circ} \mathrm{N}, 105^{\circ} \mathrm{W}\right)$ and Kauai $\left(21^{\circ} \mathrm{N}, 160^{\circ} \mathrm{W}\right)$ from left to right during the 2005-2006 northern hemispheric winter. The dotted line indicates the day of peak warming (12 January) over the polar caps.

Aleutians). The westward tilt in the anticyclone and cyclone can also be observed. In 2009, the vortex is clearly split with two cells of the split vortex existing between latitudes (going clockwise) $45-135^{\circ} \mathrm{W}$ and $135-45^{\circ} \mathrm{E}$. The anticyclone is most predominant (going anti-clockwise) between $135^{\circ} \mathrm{E}$ and $135^{\circ} \mathrm{W}$ and between $45^{\circ} \mathrm{E}$ and $45^{\circ} \mathrm{W}$. As the altitude increases, the anticyclone appears more westward and poleward and the vortex tilted westward as we go higher in altitude indicating westward planetary wave propagation. With increasing altitude, the anticyclone over the Atlantic (between $45^{\circ} \mathrm{E}-45^{\circ} \mathrm{W}$ ) appears stronger than the anticyclone over the pacific (between $135^{\circ} \mathrm{E}$ and $135^{\circ} \mathrm{W}$ ) and hence is the primary driver for the SSW and mesospheric cooling during the 2009 SSW event.

In Figs. 9 and 10, we show the temperature (top panel), zonal-mean zonal wind (middle panel) and mean meridional wind (bottom panel) from SD-WACCM simulations of the 2006 and 2009 SSW events, respectively, at grid points closest to Andenes $\left(69^{\circ} \mathrm{N}, 16^{\circ} \mathrm{E}\right)-\mathrm{a}$ high latitude location (left panels), Fort Collins $\left(41^{\circ} \mathrm{N}, 105^{\circ} \mathrm{W}\right)-$ a mid-latitude location (central panels) and at Kauai $\left(21^{\circ} \mathrm{N}, 160^{\circ} \mathrm{W}\right)$ - a low latitude location (right panels). The locations are marked by a red star and labeled in the top panels of Fig. 8. The choice of locations were motivated by previous studies from these locations, the presence of active instruments, and their geographic relevance. Hoffman et al. (2007) and Matthias et al. (2013) have previously shown wind measurements from Andenes during the 2006 and 2009 SSWs, while the Colorado State University (CSU) temperature and winds were shown by lidar measurements during the 2009 SSW event by Yuan et al. (2012). Pancheva et al. (2008) have shown wind measurements from Kauai during the 2003-2004 SSW event. During the 2006 and 2009 events there is an anticyclone over the Pacific and hence the effects of the SSW were most likely to be seen in a low latitude location such as Kauai situated equatorward of the anticyclone. The dashed line indicates the day of peak warming (12 January in 2006 and 22 January in 2009) over the polar caps. 
2008/2009 Winter
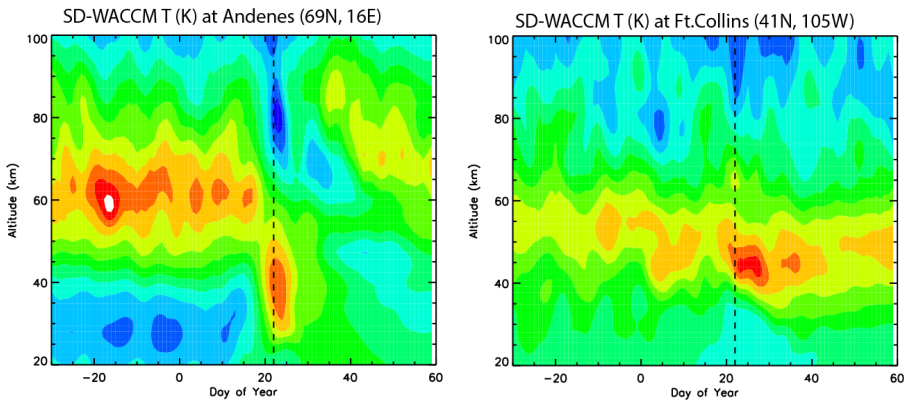

$\mathrm{SD}-\mathrm{WACCM} \mathrm{U}(\mathrm{m} / \mathrm{s})$ at Andenes $(69 \mathrm{~N}, 16 \mathrm{E})$
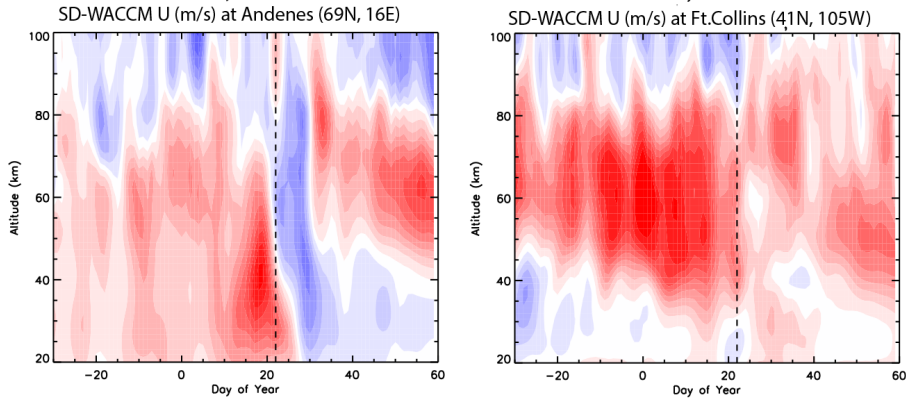

SD-WACCM V $(\mathrm{m} / \mathrm{s})$ at Andenes $(69 \mathrm{~N}, 16 \mathrm{E})$
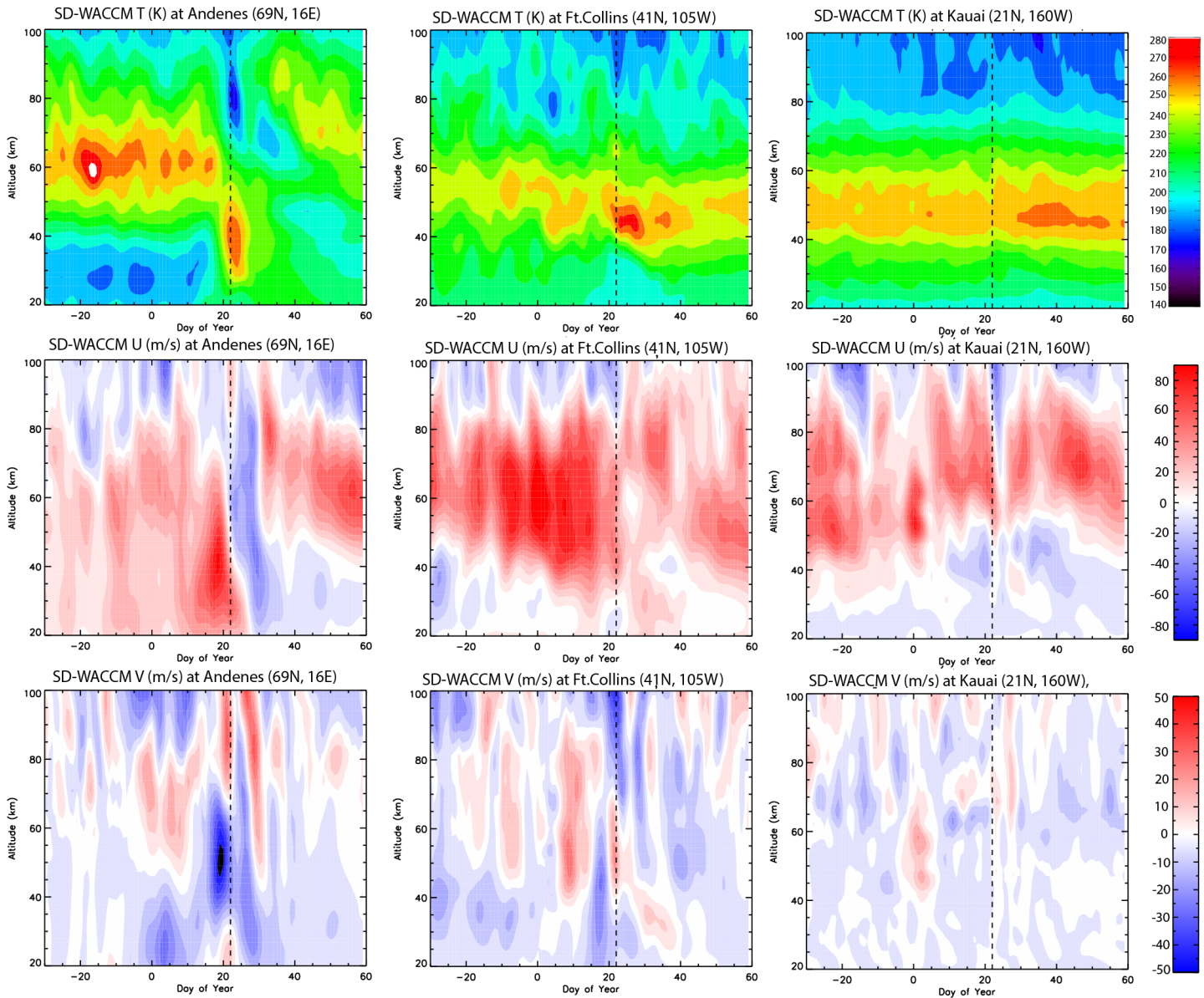

Figure 10. The temperature (top panel), zonal-mean zonal wind (middle panel) and mean meridional wind (bottom panel) from the WACCM at grid points closest to Andenes $\left(69^{\circ} \mathrm{N}, 16^{\circ} \mathrm{E}\right)$, Fort Collins $\left(41^{\circ} \mathrm{N}, 105^{\circ} \mathrm{W}\right)$ and Kauai $\left(21^{\circ} \mathrm{N}, 160^{\circ} \mathrm{W}\right)$ from left to right during the 2008-2009 northern hemispheric winter. The dotted line indicates the day of peak warming (22 January) over the polar caps.

From the left panels in Figs. 9 and 10, it can be seen that the SSW is most strongly observed in temperature and wind reversals at the high latitude location of Andenes. The stratospheric warming is higher $(\sim 300 \mathrm{~K})$ during the $2006 \mathrm{SSW}$ than in the $2009 \mathrm{SSW}(\sim 270 \mathrm{~K})$. The zonal-mean wind also reverses during both the events. Interestingly the meridional winds during the 2006 and 2009 are opposite in phase in both the upper stratosphere and MLT. Normally over the polar cap, during an SSW event, it would be expected to see poleward flow in the upper stratosphere (resulting in downwelling over the polar cap) and equatorward flow in the MLT (resulting from upwelling over the polar cap); however this assumes the downwelling and upwelling are occurring centered over the pole. During the 2006 SSW, as can be seen by the location of the anticyclone over the Aleutians in Fig. 8, the peak stratospheric downwelling and mesospheric upwelling are occurring centered at $\sim 70^{\circ} \mathrm{N}$ and $180^{\circ}$ longitude. Hence over Andenes, a poleward flow in the upper stratosphere and equatorward flow in the MLT is observed. Hoffmann et al. (2007) noted that wind observations at Andenes and Resolute Bay $\left(75^{\circ} \mathrm{N}, 95^{\circ} \mathrm{W}\right)$ during the $2006 \mathrm{SSW}$ (their Fig. 6) are in opposite phases in the MLT. This is understandable since the anticyclone is located equatorward of the Resolute Bay location. During the 2009 SSW, the anticyclone (where the upper stratosphere downwelling and MLT upwelling is occurring) is located equatorward of Andenes at $\sim 60^{\circ} \mathrm{N}$ and $0-20^{\circ} \mathrm{E}$ longitudes. Hence the meridional wind observations at Andenes show equatorward flow in the stratosphere and poleward flow in the MLT region.

The SSW event can be seen in temperature and winds at the mid-latitude location (CSU) located at $\sim 40^{\circ} \mathrm{N}$ in both 2006 and 2009. The warming effect in temperature is higher during the 2009 event $(\sim 270 \mathrm{~K})$ than during the 2006 event $(\sim 260 \mathrm{~K})$. During the $2006 \mathrm{SSW}$, the zonal-mean zonal wind reverses below $50 \mathrm{~km}$, while only a weakening of the zonalmean zonal wind is seen during the 2009 event. It is interesting to note that the model captures the mesospheric cooling by $\sim 30 \mathrm{~K}$ from climatological values observed at Fort Collins during the 2009 event (Yuan et al., 2012). The meridional wind showing equatorward flow in both stratosphere 
and MLT is consistent with the pattern see in Fig. 4f. At the low latitude site at Kauai the upper stratosphere warms by $\sim 10 \mathrm{~K}$ during the $2006 \mathrm{SSW}$ and by $\sim 4-5 \mathrm{~K}$ during the 2009 SSW. The zonal-mean wind also weakens and even reverses in the lower stratosphere at Kauai during both the events. The meridional wind shows variability, which is along similar patterns as seen in the zonal-mean wind plots of Figs. 1, 4 and 5.

\section{Summary and discussion}

While the effects of SSW events are most evident in the high latitudes, where the changes in residual circulation are magnified by the relatively smaller area compared to the midand low latitudes, SSW effects can also produce significant changes in mid- and low latitude temperature and winds. In this study we quantify these changes during SSW events from a composite of SSW events between 1988 and 2010. The changes in temperature during SSW events can be summarized as follows: poleward of $40^{\circ} \mathrm{N}$ there is warming in the stratosphere below $60 \mathrm{~km}$ and cooling at $60-100 \mathrm{~km}$. In the mid- and low latitude stratosphere there is cooling below $60 \mathrm{~km}$ while there is warming at $60-90 \mathrm{~km}$. These stratospheric cooling and mesospheric warming regions also extend into the low latitudes in the Southern Hemisphere.

The changes in the zonal-mean zonal wind can be summarized as follows: in the Northern Hemisphere, poleward of $40^{\circ} \mathrm{N}$, in the upper stratosphere and lower mesosphere $(\sim 30-85 \mathrm{~km})$ there is a westward acceleration of the zonalmean flow and in the upper MLT $(\sim 85-100 \mathrm{~km})$ there is an eastward acceleration of the zonal-mean flow. At $20-40^{\circ} \mathrm{N}$ there is a westward acceleration, or deceleration, of the eastward zonal-mean flow. In the lower latitudes $\left(0-20^{\circ} \mathrm{N}\right)$, there is an eastward acceleration below $40 \mathrm{~km}$, westward acceleration at $40-60 \mathrm{~km}$ and eastward acceleration at $60-100 \mathrm{~km}$. In the low latitudes of the Southern Hemisphere there is westward acceleration in the zonal-mean flow at $40-65 \mathrm{~km}$ and an eastward acceleration of the zonal-mean flow at $65-100 \mathrm{~km}$. The meridional wind changes can be summarized as follows: poleward of $40^{\circ} \mathrm{N}$, there is a reversal of the middle atmosphere pole-to-pole flow, which becomes equatorward. There is a deceleration of pole-to-pole flow in the middle and low latitude middle atmosphere, which extends to the southern hemispheric low latitudes as well. There is also a poleward flow in the northern hemispheric stratosphere in the low and middle latitudes $\left(0-40^{\circ} \mathrm{N}\right)$

While the above summary of changes in temperature and zonal-mean wind prevails for most SSW events, there may be differences in observed zonal-mean winds and temperature depending on location within the displaced or split polar vortex depending on the triggering planetary wave activity being PW1 or PW2. During SSW the vortex is displaced (during PW1 events) or split (during PW2 events) and lies off the pole and usually lies in one hemisphere, while the other hemisphere will have an anti-cyclonic flow. In regions where the polar vortex still exists, the mid-latitude zonal winds still remain eastward in the stratosphere and westward in the mesosphere, while in the opposite hemisphere the midlatitude winds would have reversed in both the stratosphere and mesosphere. Observations from individual mid-, low and high latitude sites have to be interpreted with respect to their location within or outside the displaced or split polar vortex. So it is entirely possible that such locations might see reversals in zonal-mean winds, warming/cooling in the stratosphere/mesosphere during one SSW event while not observing such effects during another SSW event which may look very similar while analyzed in the zonal mean. The location of the anticyclone driving the SSW and mesospheric cooling can affect meridional wind observations at high latitude sites depending on whether the anticyclone is located equatorward or poleward of the observing site.

Planetary waves show upward and equatorward propagation originating from mid-high latitudes during SSW. The planetary waves also propagate into the mid-latitude MLT region and can produce significant westward forcing reaching peak values of $\sim 60-70 \mathrm{~m} \mathrm{~s}^{-1} \mathrm{day}^{-1}$. It remains to be investigated if the planetary waves propagating to the MLT region are secondary planetary waves generated due to wind reversals in the upper stratosphere and lower mesosphere causing the presence of instabilities or planetary waves propagating from the troposphere and lower stratosphere. The propagation of these planetary waves in the tropical stratosphere depends on the phase of the QBO. During the easterly phase of the $\mathrm{QBO}$, there is propagation of these planetary waves (originating in the high latitudes) in the stratosphere across the equator, while in the westerly phase of the QBO, the planetary waves break at $\sim 20-25^{\circ} \mathrm{N}$ and there is no propagation across the equator. Hence a spectral analysis of winds at the low latitudes during the easterly phase of the QBO could indicate the presence of planetary waves with periods comparable to the ones causing the onset of the SSW as in 2005-2006 and reported on by Vineeth et al. (2010). However, our analysis indicates that the planetary wave propagation is equatorward from the mid-high latitudes during the SSW events and gives no indication of poleward propagation of planetary waves in the tropics as reported by Vineeth et al. (2010). The effects of the planetary wave propagation across the tropical stratosphere during the easterly phase of the QBO have been reported during the early winter months of November and December (Ortland, 1997; O'Sullvan, 1997). This study indicates a similar pattern of planetary wave propagation during SSW events with implications for contribution to the QBO's momentum budget (Dunkerton, 1983), constituent mixing and transport between the extratropics and tropics. The penetration of planetary waves into the tropical stratosphere during the easterly phase of the QBO affects the residual circulation by reducing the tropical upwelling and poleward flow in the upper stratosphere. 
Acknowledgements. The authors thank R. R. Garcia and V. S. Nair for helpful discussion and D. E. Kinnison for the SD-WACCM runs. The authors acknowledge support from the United States National Science Foundation (NSF) under grant ARC 1107498. AC conducted this work as a participant in the visiting scientist program at the National Center for Atmospheric Research (NCAR). Computing resources were provided by NCAR's Climate Simulation Laboratory. NCAR is supported by the NSF. The Community Earth System Model (CESM) is supported by NSF and the Office of Science of the U.S. Department of Energy.

Topical Editor C. Jacobi thanks V. Matthias and two anonymous referees for their help in evaluating this paper.

\section{References}

Andrews, D. G., Holton, J. R., and Leovy, C. B.: Middle Atmosphere Dynamics, 1st Edn., 5-6, Elsevier, New York, 1987.

Baldwin, M. P. and Dunkerton, T. J.: Stratospheric harbingers of anomalous weather regimes, Science, 294, 581-584, 2001.

Baldwin, M. P., Gray, L. J., Dunkerton, T. J., Hamilton, K., Haynes, P. H., Randel, W. J., Holton, J. R., Alexander, M. J., Hirota, I., Horinouchi, T., Jones, D. B. A., Kinnersley, J. S., Marquardt, C., Sato, K., and Takahashi, M.: The quasi-biennial oscillation, Rev. Geophysics, 39, 179-230, 2001.

Butler, A. H. and Polvani, L. M.: El Niño, La Niña, and stratospheric sudden warmings: A reevaluation in light of the observational record, Geophys. Res. Lett., 38, L13807, doi:10.1029/2011GL048084, 2011.

Chandran, A., Collins, R. L., Garcia, R. R., and Marsh, D. R.: A case study of a spontaneously generated elevated stratopause generated in the Whole Atmosphere Community Climate Model, Geophys. Res. Lett., 38, L08804, doi:10.1029/2010GL046566, 2011.

Chandran, A., Collins, R. L., Garcia, R. R., Marsh, D. R., Harvey, V. L., Yue, J., and de la Torre, L.: A climatology of elevated stratopause events in the whole atmosphere community climate model, J. Geophys. Res.-Atmos., 118, 1234-1246, doi:10.1002/jgrd.50123, 2013a.

Chandran, A., Garcia, R. R., Collins, R. L., and Chang, L. C.: Secondary planetary waves in the middle and upper atmosphere following the stratospheric sudden warming event of January 2012, Geophys. Res. Lett., 40, 1861-1867, doi:10.1002/grl.50373, 2013b.

Chandran, A., Collins, R. L., and Harvey L. V.: Stratospheremesosphere coupling during Stratospheric sudden warmings, Adv. Space Res., 53, 1265-1289, doi:10.1016/j.asr.2014.02.005, 2014.

Chen, X., Hu, X., and Xiao, C.: Variability of MLT winds and waves over mid-latitude during the 2000/2001 and 2009/2010 winter stratospheric sudden warming, Ann. Geophys., 30, 991-1001, doi:10.5194/angeo-30-991-2012, 2012.

De la Torre, L., Garcia, R. R., Barriopedro, D., and Chandran, A.: Climatology and characteristics of stratospheric sudden warmings in the Whole Atmosphere Community Climate Model, J. Geophys. Res., 117, D04110, doi:10.1029/2011JD016840, 2012.

Dunkerton, T. J.: Laterally propagating Rossby waves in the easterly acceleration phase of the quasi-biennial oscillation, Atmos. Ocean., 21, 55-68, 1983.
Fritz, S. and Soules, S. D.: Large-Scale Temperature Changes in the Stratosphere Observed from Nimbus III, J. Atmos. Sci., 27, 1091-1097, 1970.

Garcia, R. R.: On the Mean Meridional Circulation of the Middle Atmosphere, J. Atmos. Sci., 44, 3599-3609, 1987.

Garcia, R. R., Marsh, D. R., Kinnison, D. E., Boville, B. A., and Sassi, F.: Simulation of secular trends in the middle atmosphere, 1950-2003, J. Geophys. Res., 112, D09301, doi:10.1029/2006JD007485, 2007.

Gómez-Escolar, M., Calvo, N., Barriopedro, D., and Fueglistaler, S.: Tropical Response to Stratospheric Sudden Warmings and its modulation by the QBO, J. Geophys. Res.-Atmos., online first, doi:10.1002/2013JD020560, 2014.

Goncharenko, L. P., Chau, J. L., Liu, H.-L., and Coster, A. J.: Unexpected connections between the stratosphere and ionosphere, Geophys. Res. Lett., 37, L10101, doi:10.1029/2010GL043125, 2010.

Hoffmann, P., Singer, W., Keuer, D., Hocking, W. K., Kunze, M., and Murayama, Y.: Latitudinal and longitudinal variability of mesospheric winds and temperatures during stratospheric warming events, J. Atmos. Sol.-Terr. Phys., 69, 2355-2366, 2007.

Karlsson, B., McLandress, C., and Shepherd, T. G.: Interhemispheric meso- spheric coupling in a comprehensive middle atmosphere model, J. Atmos. Sol.-Terr. Phys., 71, 518-530, 2009.

Kodera, K.: Influence of stratospheric sudden warming on the equatorial troposphere, Geophys. Res. Lett., 33, L06804, doi:10.1029/2005GL024510, 2006.

Kornich, H. and Becker, B.: A simple model for the interhemispheric coupling of the middle atmosphere circulation, Adv Space Res., 45, 661-668, doi:10.1016/ j.asr.2009.11.001, 2010.

Liu, H.-L., Marsh, D. R., She, C.-Y., Wu, Q., and Xu, J.: Momentum balance and gravity wave forcing in the mesosphere and lower thermosphere, Geophys. Res. Lett., 36, L07805, doi:10.1029/2009GL037252, 2009.

Manney, G. L., Krüger, K., Pawson, S., Minschwaner, K., Schwartz, M. J., Daffer, W. H., Livesey, N. J., Mlynczak, M. G., Remsberg, E. E., Russell, J. M., and Waters, J. W.: The evolution of the stratopause during the 2006 major warming: satellite data and assimilated meteorological analyses, J. Geophys. Res., 113, 116, 2008.

Manney, G. L., Schwartz, M. J., Krüger, K., Santee, M. L., Pawson, S., Lee, J. N., Daffer, W. H., Fuller, R. A., and Livesey, N. J.: Aura Microwave Limb Sounder observations of dynamics and transport during the record-breaking 2009 Arctic stratospheric major warming, Geophys. Res. Lett., 36, L12815, doi:10.1029/2009GL038586, 2009.

Manney, G. L., Santee, M. L., Rex, M., et al.: Unprecedented Arctic ozone loss in 2011, Nature, 478, 469-475, doi:10.1038/nature10556, 2011.

Marsh, D. R.: Chemical-dynamical coupling in the Mesosphere and Lower Thermosphere, in: Aeronomy of the Earth's Atmosphere and Ionosphere, IAGA Special Sopron Book Ser., Vol. 2, edited by: Abdu, M., Pancheva, D., Bhattacharyya, A., 1st Edn., 370 pp., ISBN: 978-94-007-0325-4, Springer, Dordrecht, 2011.

Matsuno, T.: Vertical propagation of stationary planetary waves in the winter Northern Hemisphere, J. Atmos. Sci., 37, 871-883, 1970 . 
Matthias, V., Hoffmann, P., Manson, A., Meek, C., Stober, G., Brown, P., and Rapp, M.: The impact of planetary waves on the latitudinal displacement of sudden stratospheric warmings, Ann. Geophys., 31, 1397-1415, doi:10.5194/angeo-31-13972013, 2013.

McLandress, C., Scinocca, J. F., Shepherd, T. G., Reader, M. C., and Manney, G. L.: Dynamical Control of the Mesosphere by Orographic and Nonorographic Gravity Wave Drag during the Extended Northern Winters of 2006 and 2009, J. Atmos. Sci., 70, 2152-2169, doi:10.1175/JAS-D-12-0297.1, 2013.

Nath, D., Sridharan, S., Sathishkumar, S., Gurubaran, S., and Chen, W.: Lower stratospheric gravity wave activity over Gadanki $\left(13.5^{\circ} \mathrm{N}, 79.2^{\circ} \mathrm{E}\right)$ during the stratospheric sudden warming of 2009: Link with potential vorticity intrusion near Indian sector, J. Atmos. Sol. Terr. Phys., 94, 54-64, 2013.

O'Sullivan, D.: Cross-equatorially radiating stratospheric Rossby waves, Geophys. Res. Lett., 24, 1483-1486, 1997.

Ortland, D. A.: Rossby wave propagation into the tropical stratosphere observed by the High Resolution Doppler Imager, Geophys. Res. Lett., 24, 1999-2002, 1997.

Pancheva, D., Mukhtarov, P., Mitchell, N. J., Andonov, B., Merzlyakov, E., Singer, W., Murayama, Y., Kawamura, S., Xiong, J., Wan, W., Hocking, W., Fritts, D., Riggin, D., Meek, C., and Manson, A.: Latitudinal wave coupling of the stratosphere and mesosphere during the major stratospheric warming in 2003/2004, Ann. Geophys., 26, 467-483, doi:10.5194/angeo-26-467-2008, 2008.

Pawson, S., Meyer, A., and Leder, S.: Internal variability in a perpetual January integration of a troposphere-stratosphere-mesophere GCM, Q. J. Roy. Meteorol. Soc., 121, 369-397, 1995.

Richter, J. H., Sassi, F., Garcia, R. R., Matthes, K., and Fischer, C. A.: Dynamics of the middle atmosphere as simulated by the Whole Atmosphere Community Climate Model, version 3 (WACCM3), J. Geophys. Res., 113, D08101, doi:10.1029/2007JD009269, 2008.

Richter, J. H., Sassi, F., and Garcia, R. R.: Toward a physically based gravity wave source parameterization in a General Circulation Model, J. Atmos. Sci., 67, 136-156, 2010.

Salmi, S.-M., Verronen, P. T., Thölix, L., Kyrölä, E., Backman, L., Karpechko, A. Yu., and Seppälä, A.: Mesosphere-to-stratosphere descent of odd nitrogen in February-March 2009 after sudden stratospheric warming, Atmos. Chem. Phys., 11, 4645-4655, doi:10.5194/acp-11-4645-2011, 2011.
Sathishkumar, S. and Sridharan, S.: Planetary and gravity waves in the mesosphere and lower thermosphere region over Tirunelveli $\left(8.7^{\circ} \mathrm{N}, 77.8^{\circ} \mathrm{E}\right)$ during stratospheric warming events, Geophys. Res. Lett., 36, L07806, doi:10.1029/2008GL037081, 2009.

Sathishkumar, S., Sridharan, S., and Jacobi, Ch.: Dynamical response of low-latitude middle atmosphere to major sudden stratospheric warming events, J. Atmos. Sol.-Terr. Phys., 71, 857-865, 2009.

Siskind, D. E., Eckermann, S. D., Coy, L., and McCormack, J. P.: On recent interannual variability of the Arctic winter mesosphere: Implications for tracer descent, Geophys. Res. Lett., 34, L09806, doi:10.1029/2007GL029293, 2007.

Siskind, D. E., Eckermann, S. D., McCormack, J. P., Coy, L., Hoppel, K. W., and Baker, N. L.: Case studies of the mesospheric response to recent minor, major, and extended stratospheric warmings, J. Geophys. Res., 115, D00N03, doi:10.1029/2010JD014114, 2010.

Sridharan, S., Raghunath, K., Sathishkumar, S., and Nath, D.: First results of war mesospheric temperature over Gadanki $\left(13.51^{\circ} \mathrm{N}, 79.21^{\circ} \mathrm{E}\right)$ during the sudden stratospheric warming of 2009, J. Atmos. Sol.-Terr. Phys., 72, 1139-1146, doi:10.1016/j.jastp.2010.06.003, 2010.

Vineeth, C., Pant, T. K., Kumar, K. K., and Sumod, S. G.: Tropical connection to the polar stratospheric sudden warming through quasi 16-day planetary wave, Ann. Geophys., 28, 2007-2013, doi:10.5194/angeo-28-2007-2010, 2010.

Yuan, T., She, C.-Y., Krueger, D. A., Sassi, F., Garcia, R., Roble, R. G., Liu, H.-L., and Schmidt, H.: Climatology of mesopause region temperature, zonal wind, and meridional wind over Fort Collins, Colorado $\left(41^{\circ} \mathrm{N}, 105^{\circ} \mathrm{W}\right)$, and comparison with model simulations, J. Geophys. Res., 113, D03105, doi:10.1029/2007JD008697, 2008.

Yuan, T., Thurairajah, B., She, C.-Y., Chandran, A., Collins, R. L., and Krueger, D. A.: Wind and temperature response of midlatitude mesopause region to the 2009 Sudden Stratospheric Warming, J. Geophys. Res., 117, D09114, doi:10.1029/2011JD017142, 2012. 